\title{
Corrosion Evaluation of Orthodontic Wires in Artificial Saliva Solutions by Using Response Surface Methodology
}

\author{
Arianne Madureira Barcelos ${ }^{\mathrm{a}}$, Aderval Severino Luna ${ }^{\mathrm{a}}$, Nancy de Assis Ferreira ${ }^{\mathrm{b}}$, \\ Antônio Vitor Castro Braga ${ }^{\text {a }}$ Dalva Cristina Baptista do Lago ${ }^{\text {a }}$ Lilian Ferreira de Senna*

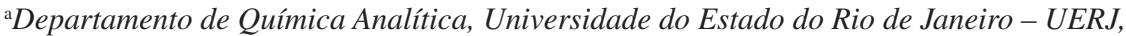 \\ Rua São Francisco Xavier, 524, Sala 427, Pavilhão Haroldo Lisboa da Cunha, \\ Maracanã, CEP 20559-013, Rio de Janeiro, RJ, Brasil \\ ${ }^{\mathrm{b}}$ Faculdade de Odontologia, Universidade do Estado do Rio de Janeiro - UERJ, \\ Av. Boulevard 28 de Setembro, 157, Vila Isabel, CEP 20551-030, Rio de Janeiro, RJ, Brasil
}

Received: February 3, 2012; Revised: July 19, 2012

\begin{abstract}
In the present work, stainless steel and $\mathrm{Ni}$ - Ti commercial orthodontic wires were immersed in artificial saliva solutions, containing or not $\mathrm{F}^{-}$ions, in different $\mathrm{pH}$ values, during 30 days. The weight loss and the $\mathrm{Ni}^{2+}$ content in the solutions at 15 and 30 days of exposition were evaluated using a composite design $2^{3}$ and response surface methodology. The open circuit potential (OCP) was measured over the same period of time. Polarization curves and morphological analysis of the wires before and after the corrosion experiments were also carried out. The results showed that corrosion of the studied metal alloys depended on a combination among saliva $\mathrm{pH}$, the exposition time, and the concentration of $\mathrm{F}^{-}$ions in the solution. The critical condition was observed for $\mathrm{Ni}-\mathrm{Ti}$ wires at $\mathrm{pH}=3.0$, and high concentration of $\mathrm{F}^{-}$ions, causing a decrease in the OCP values and an increase in Ni dissolution and corrosion current density.
\end{abstract}

Keywords: orthodontic wires, corrosion, experimental design, artificial saliva

\section{Introduction}

Titanium alloys such as TMA (Ti-Mo-Sn-Zr), Ti-Nb, $\mathrm{Ni}-\mathrm{Ti}$ and $\mathrm{Cu}-\mathrm{Ni}$-Ti are generally used as biomaterials, mainly as orthodontic wires, because of their interesting elasticity and shape memory capacity, which allow these materials to return to their original configurations after being submitted to a stress ${ }^{1-5}$. These properties, that are not observed in the traditionally used stainless steel wires (generally called $\mathrm{Cr}-\mathrm{Ni}$ wires by the dentists), permit the orthodontist to apply continuous forces on the teeth, without causing discomfort to the patient. This is a positive aspect and stimulated the use of titanium alloys wires instead of stainless steel ones, mainly during the beginning of the treatment, when the teeth are more misaligned.

However, Ni-Ti-based alloys present a large Ni content (about $48-55 \%$ mass), and a negative aspect that hinders their wide use in prolonged orthodontic treatment takes into account the $\mathrm{Ni}$ corrosion in oral cavity. This point is a constant concern of many Dentistry professionals, since the presence of the ion $\mathrm{Ni}^{2+}$ in the oral medium can cause several allergies to the patients ${ }^{1,6}$. It implies that corrosion resistance must be another important item to be estimated for the prolonged using of these materials in orthodontic treatments.

Indeed, the anticorrosive behavior of $\mathrm{Ni}$-Ti-based wires has been evaluated in several works ${ }^{5,7-10}$, which presented

\footnotetext{
*e-mail: 1senna@uerj.br
}

different results, in the great majority of the cases. Kim and Johnson $^{7}$ analyzed the breakdown potential of stainless steel, $\mathrm{Ni}-\mathrm{Ti}$, and titanium orthodontic wires in $0.9 \% \mathrm{~m} / \mathrm{v} \mathrm{NaCl}$. Two different samples of each kind of wire were analyzed and the results indicated that the corrosion occurred readily on both samples of stainless steel. On the other hand, the $\mathrm{Ni}$-Ti wires breakdown potential depended on the wires' manufacturer, showing a dubious result compared to stainless steel. Kuhta et al. ${ }^{11}$ studied the release of $\mathrm{Ni}^{2+}$ from $\mathrm{Ni}-\mathrm{Ti}$ and stainless steel wires in artificial saliva $(\mathrm{pH}=6.75$ and $\mathrm{pH}=3.5$ ). The $\mathrm{Ni}^{2+}$ content released from stainless steel was higher than the amount released from $\mathrm{Ni}-\mathrm{Ti}$ alloys at $\mathrm{pH}=6.75$, while an opposite result was found for $\mathrm{pH}=3.5$. The amount of $\mathrm{Ni}^{2+}$ released decreased with the exposition time for both wires, regardless the $\mathrm{pH}$ value. Kao and Huang ${ }^{12}$ compared the corrosion behaviour of stainless steel and Ni-Ti wires in fluoridated artificial saliva at two $\mathrm{pH}$ values, 4 and 6 , and their results indicated that both wires were easily corroded in the $\mathrm{pH}=4$ artificial saliva, without any significant variance. The SEM morphological analysis showed that both materials presented pitting corrosion on their surfaces. Schiff et al. ${ }^{5}$ compared the performance of TMA, Ti-Nb, Ni-Ti, and $\mathrm{Cu}-\mathrm{Ni}-\mathrm{Ti}$ wires in artificial saliva $(\mathrm{pH}=5.3)$ and commercial mouthwashes, by using polarization curves and OCP measurements. The results indicated that the reactivity of each Ti-alloy wire depended 
on the kind of mouthwash used. It is important to point out that each result was obtained with different $\mathrm{Ni}$-Ti-based alloys (different chemical composition and manufacturing processes), saliva solutions, $\mathrm{pH}$ values, and $\mathrm{F}^{-}$concentration (when present), which makes it difficult to obtain a careful evaluation of the different effects that these parameters exert in the variables related to the corrosion resistance of the mentioned alloys in the simulated saliva medium.

In addition, there is not a consensus in the literature concerning the validity of in vitro experiments to evaluate the $\mathrm{Ni}^{2+}$ release in $\mathrm{Ni}$-Ti-based alloys. It is claimed that the in vitro works have no comparison to actual in vivo conditions, since the handling and manipulation of materials in the laboratory lacks the formation of biofilms on materials, which might decrease the reactivity of materials with the environment. Moreover, the exposition time in the aggressive medium is considered very small and should last from 1.5 to 36 months, which is the real period of a complete orthodontic treatment ${ }^{13,14}$. In fact, the period of typical orthodontic treatment of 2-3 years is such that both the effect of fatigue and corrosion, which are substances of time, should be also considered in each study concerning the $\mathrm{Ni}^{2+}$ content in the saliva ${ }^{14,15}$. Amini et al. ${ }^{16}$ have conducted an experiment that lasted 12 to 18 months, using the saliva of human subjects with fixed orthodontic appliances and evaluated the variation in the $\mathrm{Ni}^{2+}$ content in the saliva. They also compared these results with the $\mathrm{Ni}^{2+}$ content in the saliva of subjects without a fixed orthodontic appliance and found a statically difference $(P<0.035)$ between both groups. However, the investigation of metal content in human biological fluids, such as saliva or blood, is complicated by the high individual variability and the inability to derive an estimation of the cumulative release of metals over the full term of treatment ${ }^{17}$.

Therefore, there are many parameters to be evaluated if the corrosion process of orthodontic wires can be clinically considered. In most of the in vitro works, the conventional and classical univariate methods are used to evaluate this process. In these methods, most of the parameters are maintained at constant values while one of them is varied in a chosen direction ${ }^{18}$. The use of univariate methods means that, in practice, the best conditions to avoid corrosion $(\mathrm{pH}$, $\mathrm{F}^{-}$concentration, exposition time, the wire material, the wire surface treatment, etc.) are often chosen empirically. On the other hand, in the in vivo researchers, all the parameters vary spontaneously and the results are composed by their joint effects. Its is not possible to know effectively if the salivary metal ion differences in subjects with and without orthodontic appliance may be partly attributed to dissimilarities in nutritional habits, since the effect of dietary $\mathrm{Ni}$ intake on metal content of saliva cannot be calculated ${ }^{15,16}$.

One way to achieve a better approach, given the complexity of the corrosion processes in the oral cavity, is to use experimental design and response surface methodology, in which all the parameters are varied simultaneously, showing the responses of their synergic and antagonistic interactions. These methodologies both drastically reduce the number experiments needed to optimize the process and give statistical inference on the optimum conditions ${ }^{18}$.
In the present work, experimental design and response surface methodology were used to evaluate in vitro the effects of $\mathrm{pH}$, time of exposition and the fluoride ions content on the anticorrosive behaviour of commercial orthodontic wires of stainless steel and Ni-Ti alloys in artificial saliva solutions. The chosen of these initially studied parameters was based on their presence on the majority of the works concerning corrosion of orthodontic appliance in the literature ${ }^{4,5,7,12}$. Additionally, open circuit potential (OCP) measurements, polarization curves, and morphological analysis were also carried out. Our goal was to contribute to a better understanding of the corrosion problems of the stainless steel and $\mathrm{Ni}-\mathrm{Ti}$ archwires in an artificial saliva medium by using statistic evaluation, reaching to a more quantitative result. Moreover, this work aims to add the use of experimental design and response surface methodology to the discussion concerning the long term use of $\mathrm{Ni}$-Ti wires in orthodontic treatment.

\section{Experimental Procedures}

\subsection{Stainless steel and Ni-Ti wires}

Commercial orthodontic stainless steel (SS) and Ni-Ti wires (Morelli Ortodontia, Rio de Janeiro, Brazil) were used in this work. The SS wire was an austenitic stainless steel ABNT $302^{[19]}$, whose chemical composition is described in Table 1. The bright polished finishing was obtained by drawing the material in diamond tool. No quantitative specification concerning the roughness of the wires was provided by the manufacturer.

The NiTi wire was manufactured in accordance to ASTM F 2063 ${ }^{[20]}$, and its chemical composition is presented in Table 2. The NiTi archwires were submitted to mechanical polishing after thermal treatment. Similar to SS archwires, no quantitative specification concerning the roughness of the wires was provided by the manufacturer.

\subsection{Total immersion experiments}

The wires' samples used in these experiments (both SS and $\mathrm{Ni}$-Ti wires) presented $0.5 \mathrm{~mm}$ diameter and $6.0 \mathrm{~cm}$ length. They were first cleaned with acetone, dried in warm air, and weighted with an analytical balance (Sartorius BL210, with $0.1 \mathrm{mg}$ precision). Then, the wires were immersed in $25.00 \mathrm{~mL}$ of artificial saliva solutions (Table 3), which were produced based on the work of Ferreira ${ }^{3}$. The $\mathrm{pH}$ solutions (3.0 or 5.0) were chosen based on the main works presented in the literature ${ }^{4,7,11}$, as well as in clinical data: the lowest $\mathrm{pH}$ value found under mature dental plaque was about $3.5^{[21]}$. The $\mathrm{pH}$ values were adjusted with a $0.1 \mathrm{~mol} . \mathrm{L}^{-1}$ $\mathrm{HCl}$ solution.

Table 1. Chemical composition of the austenitic stainless steel wire ${ }^{19}$.

\begin{tabular}{cccccccc}
\hline \multicolumn{8}{c}{ Chemical composition $(\% \mathbf{m} / \mathbf{m})$} \\
\hline $\mathbf{C}$ & $\mathbf{M n}$ & $\mathbf{S i}$ & $\mathbf{P}$ & $\mathbf{S}$ & $\mathbf{C r}$ & $\mathbf{N i}$ & $\mathbf{F e}$ \\
\hline & & & & & 17.00 & 8.00 \\
0.15 & 2.00 & 1.00 & 0.045 & 0.03 & $\begin{array}{c}\text { to } \\
\text { to }\end{array}$ & balance \\
& & & & & 19.00 & 10.00 & \\
\hline
\end{tabular}


Initially, a composite design $2^{3}$ (from known on denominated Design 1) was used to evaluate the effects of the studied wire, SS or Ni-Ti $(\boldsymbol{w})$, the solution $\mathrm{pH}(\boldsymbol{p H})$, and the exposition time to the corrosive medium $(\boldsymbol{t})$, on the weight loss $(\Delta \boldsymbol{m})$ and on the $\mathrm{Ni}^{2+}$ concentration $\left(\boldsymbol{C}_{N i}\right)$ released during the experimental time. It means that the three parameters $\boldsymbol{w}, \boldsymbol{p H}$, and $\boldsymbol{t}$ were simultaneously varied between two levels, -1 and +1 , in which the -1 level represents the lowest value of the parameter, while the +1 level corresponds to the highest value of the parameter ${ }^{18}$. The experimental design matrix, as well as the codified and the real values of the studied parameters are presented in Table 4. In this design, only solutions 1 and 2 of Table 3 were used. All experiments were carried out in duplicates to evaluate the experimental error ${ }^{18}$. At the end of the assays the wires were cleaned with water and alcohol, dried with warm air, and weighted again, using the same analytical balance. The results were used to calculate $\Delta \boldsymbol{m}$. In addition, $10.00 \mathrm{~mL}$ of the saliva solution of each experiment were analyzed by flame atomic absorption spectrometry (Perking Elmer AAnalist 300) to quantify the $\boldsymbol{C}_{N i}$ released at the studied conditions. A commercial software package (STATISTICA for Windows, release 7.0) was used for the experimental data regression analysis.
A second composite design $2^{3}$ (from now on denominated Design 2) was used, based on the solutions no. 3 to 6 from Table 3, which present $\mathrm{F}^{-}$ions in two different concentration, $100 \mathrm{mg} . \mathrm{L}^{-1}\left(5.3 \times 10^{-3}\right.$ mol.L $\left.\mathrm{L}^{-1}\right)$ and $1000 \mathrm{mg} . \mathrm{L}^{-1}\left(5.3 \times 10^{-2} \mathrm{~mol} . \mathrm{L}^{-1}\right)$. This new group of experiments intended to evaluate the effects of the studied wire $(\boldsymbol{w})$, the $\mathrm{F}^{-}$concentration $\left(\boldsymbol{C}_{\boldsymbol{F}}\right)$, and the exposition time to the corrosive medium $(t)$, on the weight loss $(\Delta m)$ and in the $C_{N i}$ released during the experimental time. All the experiments were carried out in duplicate, for each solution $\mathrm{pH}$ (3.0 or 5.0). The wires were prepared as former described for Design 1, and the procedures at the end of the experiments were also similar to those earlier mentioned. The experimental design matrix, as well as the codified and the real values of the studied parameters are presented in Table 5. The same commercial software package (STATISTICA for Windows, release 7.0) was used for the experimental data regression analysis.

The complete surface response model between the studied factors and the system response, based on both proposed experimental designs, is presented in Equation 1.

Table 2. Chemical composition of the nickel-titanium shape memory alloy wire ${ }^{20}$.

\begin{tabular}{cccccccccc}
\hline \multicolumn{10}{c}{ Chemical composition $(\% \mathbf{m} / \mathbf{m})$} \\
\hline $\mathbf{N i}$ & $\mathbf{C}_{\max }$ & $\mathbf{C o}_{\max }$ & $\mathbf{C u}_{\max }$ & $\mathbf{C r}_{\max }$ & $\mathbf{H}_{\max }$ & $\mathbf{F e}_{\max }$ & $\mathbf{N b}_{\max }$ & $(\mathbf{N}+\mathbf{O})_{\max }$ & $\mathbf{T i}$ \\
\hline 54.5 to 57.0 & 0.050 & 0.050 & 0.010 & 0.010 & 0.005 & 0,050 & 0.025 & 0.050 & Balance \\
\hline
\end{tabular}

Table 3. $\mathrm{pH}$ and chemical composition of the studied artificial saliva solutions.

\begin{tabular}{|c|c|c|c|c|c|c|}
\hline \multirow{2}{*}{ Solution no. } & \multicolumn{5}{|c|}{ Composition(mg.L $\left.\mathbf{L}^{-1}\right)$} & \multirow{2}{*}{ pH } \\
\hline & $\mathrm{K}_{2} \mathrm{HPO}_{4}$ & $\mathrm{NaCl}$ & $\mathrm{CaCl}_{2} \cdot 2 \mathrm{H}_{2} \mathrm{O}$ & $\mathrm{KCl}$ & $\mathbf{F}^{-}$ & \\
\hline 1 & 270 & 670 & 120 & 960 & - & 3.0 \\
\hline 2 & 270 & 670 & 120 & 960 & - & 5.0 \\
\hline 3 & 270 & 670 & 120 & 960 & 100 & 3.0 \\
\hline 4 & 270 & 670 & 120 & 960 & 1000 & 3.0 \\
\hline 5 & 270 & 670 & 120 & 960 & 100 & 5.0 \\
\hline 6 & 270 & 670 & 120 & 960 & 1000 & 5.0 \\
\hline
\end{tabular}

Table 4. Central composite design $2^{3}$ experimental matrix (Design 1), showing codified and normal values of the studied variables: SS or $\mathrm{Ni}$-Ti wire $(\boldsymbol{w})$, solution $\mathrm{pH}(\boldsymbol{p H})$, and exposition time $(\boldsymbol{t})$ to the solutions no. 1 and 2 of Table 3.

\begin{tabular}{ccccccc}
\hline \multirow{2}{*}{ Run no. } & \multicolumn{3}{c}{ Codified values } & \multicolumn{2}{c}{ Real values } \\
\cline { 2 - 7 } & $\mathbf{t}$ (cod.) & $\mathbf{p H}$ (cod.) & Wire (cod.) & t/days & pH & Kind of wire \\
\hline 1 & -1 & -1 & -1 & 15 & 3.0 & SS \\
2 & +1 & -1 & -1 & 30 & 3.0 & $\mathrm{SS}$ \\
3 & -1 & +1 & -1 & 15 & 5.0 & $\mathrm{SS}$ \\
4 & +1 & +1 & -1 & 30 & 5.0 & $\mathrm{SS}$ \\
5 & -1 & -1 & +1 & 15 & 3.0 & $\mathrm{Ni}-\mathrm{Ti}$ \\
6 & +1 & -1 & +1 & 30 & 3.0 & $\mathrm{Ni}-\mathrm{Ti}$ \\
7 & -1 & +1 & +1 & 15 & 5.0 & $\mathrm{Ni}-\mathrm{Ti}$ \\
8 & +1 & +1 & +1 & 30 & 5.0 & $\mathrm{Ni}-\mathrm{Ti}$ \\
\hline
\end{tabular}


$\hat{y}=b_{0}+b_{1} X_{1}+b_{2} X_{2}+b_{3} X_{3}+b_{12} X_{1} X_{2}$
$+b_{13} X_{1} X_{3}+b_{23} X_{2} X_{3}+b_{123} X_{1} X_{2} X_{3}$

where $\hat{y}$ is the estimated response $\left(C_{N i}\right.$ or $\left.\Delta m\right), X_{1}$ is the exposition time in the corrosive medium $(t), X_{2}$ represents $\boldsymbol{p H}$ (for Design 1) or $\boldsymbol{C}_{\boldsymbol{F}}$ (for Design 2), and $\mathrm{X}_{3}$ is the kind of wire studied $(w) . X_{i} X_{j}$ is the term of interaction between two of the parameters, while $\mathrm{X}_{\mathrm{i}} \mathrm{X}_{\mathrm{j}} \mathrm{X}_{\mathrm{k}}$ represents the interaction among all the studied parameters; $b_{i}$ are the equation coefficients. Statistical tests $(p=0.05)$ were then used to verify whether the analyzed effects were statistically significant ${ }^{18}$. In the Equations presented in this work only the parameters that affected the system at a level of statistical significance $(p<0.05)$ are shown. It is important to point out that even though some individuals trends could be observed in how $\boldsymbol{t}, \boldsymbol{p H}$ ( or $\boldsymbol{C}_{\boldsymbol{F}}$ ), and $\boldsymbol{w}$ influenced the system responses, the final results were obtained using the response surfaces, which take in account all the responses observed for each effect ${ }^{18}$.

\subsection{Open circuit potential (OCP) measurements}

Other samples of the same commercial SS and Ni-Ti orthodontic wires were again submitted to the cleaning treatment earlier described, before being linked to a conductor wire and embedded in acrylic resin, to produce electrodes (exposed area of $0.35 \mathrm{~cm}^{2}$ ). The electrodes were immersed in the solutions of Table 3 , and their OCP values were measured during 30 days, using a saturated calomel electrode (SCE) as the reference electrode and a multimeter (Wavetek Meterform 28XT). Each experiment was performed in triplicate.

\subsection{Polarization experiments}

Other electrodes of the same commercial orthodontic SS and $\mathrm{Ni}-\mathrm{Ti}$ wires, with exposed area of $0.35 \mathrm{~cm}^{2}$, were prepared as earlier described in item 2.3 to be used in the polarization experiments performed in the solutions of Table 3. A three-electrode cell was used in these experiments: the wires were the working electrodes, a Pt spiral was used as the counter electrode, and the saturated calomel electrode was the reference electrode. The polarization experiments were carried out in a potentiostat/galvanostat Autolab 302N, using a scan rate of $5 \mathrm{mV} / \mathrm{s}^{-1}$, from $-1 \mathrm{~V}_{\mathrm{SCE}}$ to $+1 \mathrm{~V}_{\mathrm{SCE}}$, at room temperature.

\subsection{Morphological surface analysis}

The morphologies of both wires, as-received and after the weight loss experiments, were evaluated using a scanning electron microscope (SEM - ZEISS - model EVO MA 10). The samples were cleaned with acetone, dried in warm air, and then attached to the support with a conducting tip. Only secondary electron (SE) mode was used.

\section{Results and Discussion}

\subsection{Morphology of the as-received commercial wires}

In the present work, both $\mathrm{SS}$ and $\mathrm{Ni}$-Ti wires were acquired from the same manufacturer, since we aimed to evaluate statistically the effects of the chosen parameters on these wires, only. Therefore, the differences in morphology presented here will be due to their different surface preparation, as presented in item 2.1. There was no intention in comparing their performance with other kind of wires used in orthodontic treatment or with the same wires produced by other manufactures.

Even though it is known that that corrosion of orthodontic alloys occurs in the intraoral environment regardless of the metallurgic structure of the alloy, the initial morphology of the wires (the presence of defects or high roughness, for example) can also contribute to their corrosion performance ${ }^{12,22,23}$. Therefore, Figure 1 presents the surface morphology of the as-received commercial SS and Ni-Ti wires. It is possible to observe that both wires present homogeneous surfaces, without many defects. Nevertheless, the Ni-Ti wire (Figure 1b) present small cracks and pores. Since the presence of manufacturing defects may accelerate the corrosion process ${ }^{23}$, these small defects in $\mathrm{Ni}$-Ti wires may influence their performances in aggressive environments.

\subsection{OCP measurements}

Figure 2 presents the average OCP values for the Ni-Ti and SS exposition in the artificial saliva solutions shown in Table 3 during 30 days. This exposition period was

Table 5. Central composite design $2^{3}$ experimental matrix (Design 2), showing codified and normal values of the studied variables: SS or $\mathrm{Ni}$-Ti wire $(\boldsymbol{w}), \mathrm{F}^{-}$concentration $\left(\boldsymbol{C}_{\boldsymbol{F}}\right)$, and exposition time $(\boldsymbol{t})$ to the solutions no. 3 to 6 of Table 1.

\begin{tabular}{|c|c|c|c|c|c|c|}
\hline \multirow{2}{*}{ Run no. } & \multicolumn{3}{|c|}{ Codified values } & \multicolumn{3}{|c|}{ Real values } \\
\hline & t (cod.) & $\mathrm{C}_{\mathrm{F}}(\operatorname{cod})$. & Wire (cod.) & t/days) & $\mathrm{C}_{\mathrm{F}} / \mathrm{mg} \mathrm{L}^{-1}$ & Kind of wire \\
\hline 1 & -1 & -1 & -1 & 15 & 100 & SS \\
\hline 2 & +1 & -1 & -1 & 30 & 100 & SS \\
\hline 3 & -1 & +1 & -1 & 15 & 1000 & SS \\
\hline 4 & +1 & +1 & -1 & 30 & 1000 & SS \\
\hline 5 & -1 & -1 & +1 & 15 & 100 & $\mathrm{Ni}-\mathrm{Ti}$ \\
\hline 6 & +1 & -1 & +1 & 30 & 100 & $\mathrm{Ni}-\mathrm{Ti}$ \\
\hline 7 & -1 & +1 & +1 & 15 & 1000 & $\mathrm{Ni}-\mathrm{Ti}$ \\
\hline 8 & +1 & +1 & +1 & 30 & 1000 & $\mathrm{Ni}-\mathrm{Ti}$ \\
\hline
\end{tabular}


chosen because these wires may be replaced after 1-month application, during dental orthodontic treatment $t^{4,11}$. When both wires were exposed to solutions no. 1 and 2 of Table 3 (Figure 2a), most of the OCP results are positive potentials, regardless the $\mathrm{pH}$ value used.

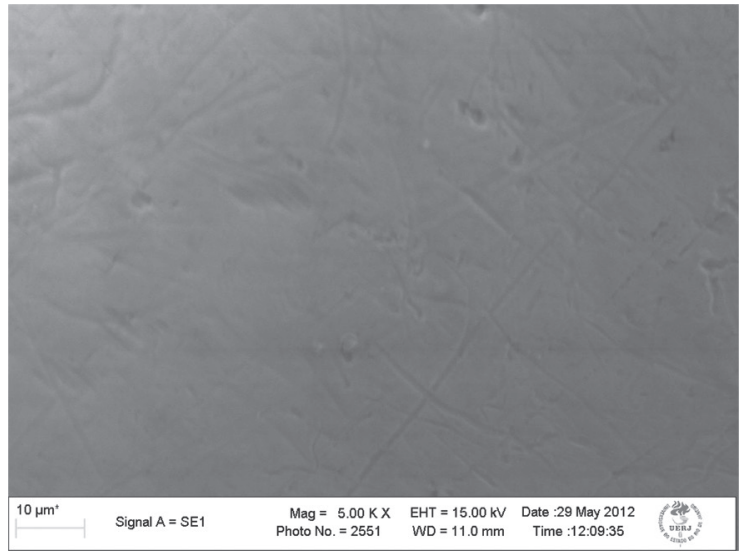

(a)
SS owes its corrosion resistance to chromium, a highly reactive base metal, which spontaneously forms (passivation) and reforms (repassivation) a passive chromium oxide film on its surface, both in air and under most tissue fluid conditions $^{23}$. The $\mathrm{Ni}$-Ti wires used in orthodontic treatments

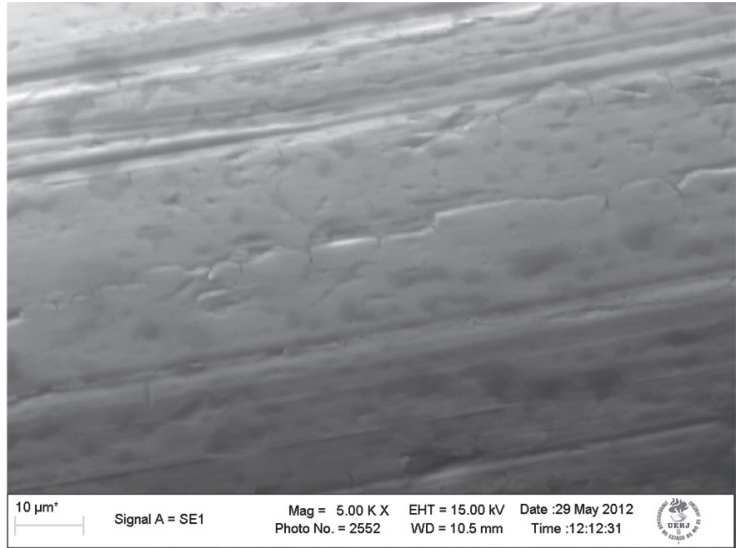

(b)

Figure 1. Surface morphologies of the (a) SS and (b) Ni-Ti wires as-received.

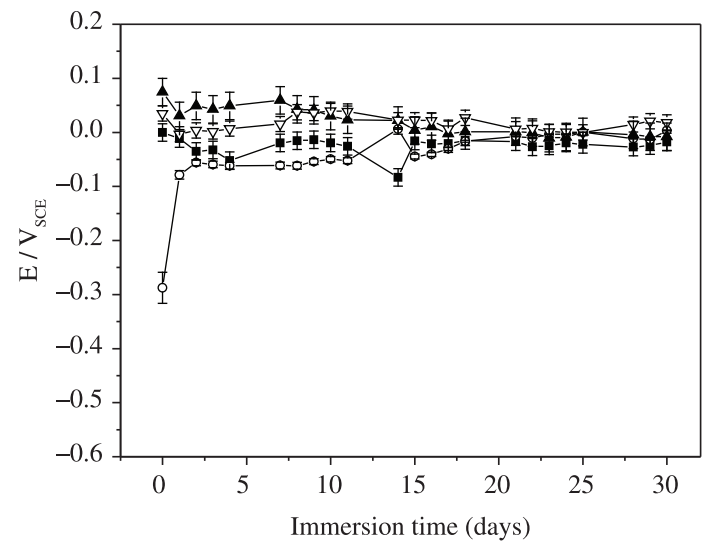

(a)

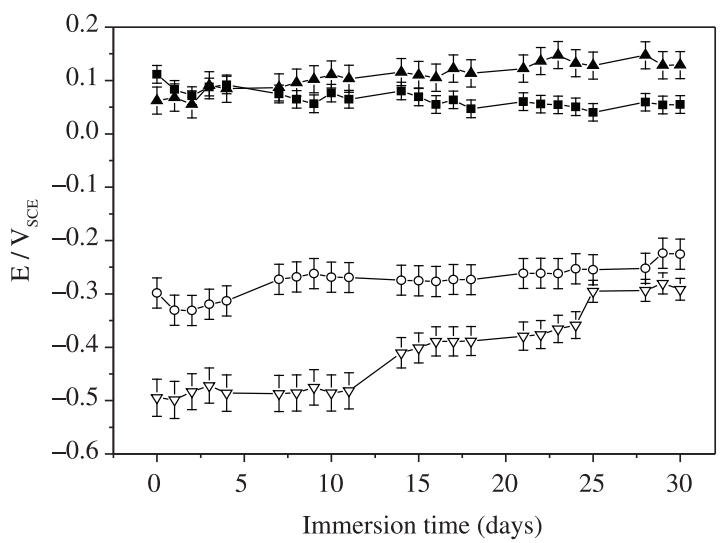

(b)

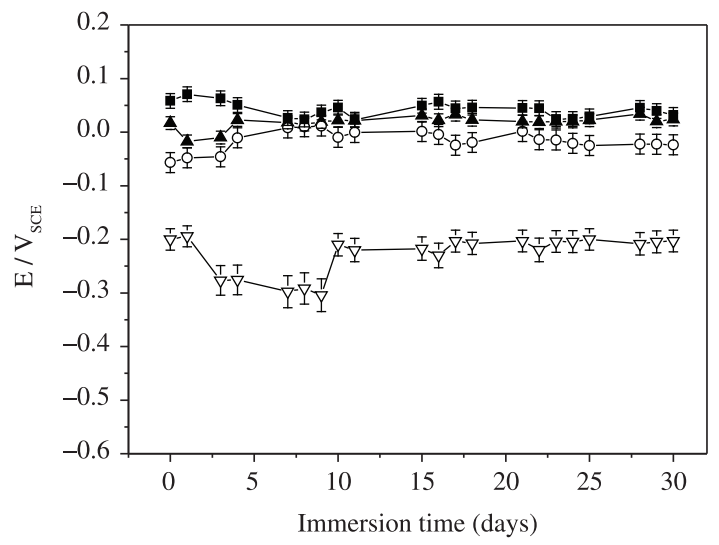

(c)

Figure 2. Average OCP measurements of $\mathrm{Cr}-\mathrm{Ni}$ and $\mathrm{Ni}-\mathrm{Ti}$ wires, obtained during 30 days of exposition in the solutions of Table 1: (a) Exposition to solutions no. 1 ( $\square \mathrm{SS}, \circ \mathrm{Ni}-\mathrm{Ti})$ and 2 ( $\Delta \mathrm{SS}, \nabla \mathrm{Ni}-\mathrm{Ti})$; (b) Exposition to solutions no. 3 (घ SS, ○ Ni-Ti) and 4 ( $\boldsymbol{\Delta} \mathrm{SS}$,

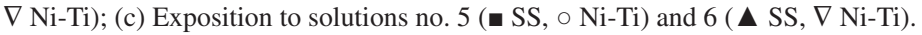


present a passive layer of titanium oxide on their surfaces due to the presence of titanium. In water, this passive layer grow, since the $\mathrm{pH}$ increasing due to the reaction $\mathrm{Ti}+2 \mathrm{H}_{2} \mathrm{O} \rightarrow \mathrm{TiO}_{2}+2 \mathrm{H}_{2}$, favors the released $\mathrm{OH}^{-}$anions to migrate to the surface and stabilize the oxide layer ${ }^{17}$.

Comparing the above mentioned results to the Pourbaix Diagrams for the studied systems (Cr-water and Ti-water, respectively $)^{24}$, the OCP values obtained for both wires in saliva $\mathrm{pH}=5.0$ are in agreement with the stability region of $\mathrm{CrO}_{2}$ and $\mathrm{TiO}_{2}$, indicating that the passive layer covering both wires might still be intact after 30 days.

Less positive OCP values were measured for the wires exposed at $\mathrm{pH}=3.0$, mainly until approximately 18 days of experiment. This result indicates that a decrease in $\mathrm{pH}$ might have caused a small deterioration of these films and, consequently, that a higher $\mathrm{Ni}^{2+}$ could have been released in this condition. It is known that acidic conditions provide a reducing environment in which the stainless steel oxide film required for corrosion resistance is less stable ${ }^{15}$. Moreover chloride ions can be particularly detrimental to these wires. Additionally, the increase in $\mathrm{H}^{+}$concentration trends to decrease the stability of $\mathrm{TiO}_{2}$ oxide on the Ni-Ti-based wires surfaces, decreasing their corrosion resistance ${ }^{24,25}$. However, at the end of the experiment, there was no significant differences on the OCP values among the wires and/or the $\mathrm{pH}$ values, showing that the $\mathrm{CrO}_{2}$ and $\mathrm{TiO}_{2}$ coatings could have probably kept their integrities, even at $\mathrm{pH}=3.0$.

$\mathrm{F}^{-}$ions were included in the artificial saliva solutions to simulate other conditions generally found in the oral cavity. Fluoride-containing commercial mouthwashes, toothpastes, and prophylactic gels are widely used to prevent dental caries and relieve dental sensitivity. Moreover, fluoride mouth rinses are effective complements to mechanical cleaning. It reduces enamel decalcification and gingival inflammation, and enhances the remineralization of enamel adjacent to orthodontic brackets ${ }^{26-28}$. It is also known, however, that $\mathrm{F}^{-}$ions are very aggressive toward the protective $\mathrm{CrO}_{2}$ and $\mathrm{TiO}_{2}$ films present on the outermost surface of SS and $\mathrm{Ni}-\mathrm{Ti}$-based wires ${ }^{3,4,12,29}$. In acidic condition, the presence of $\mathrm{F}^{-}$ions may cause pitting corrosion, since this anion may penetrate into the metal/oxide film interface ${ }^{12,30}$.

The presence of $\mathrm{F}^{-}$ions in the artificial saliva solutions of the present work (solutions 3 to 6 of Table 3 ) produced different results in the OCP measurements of the wires exposed to them. The OCP values observed for SS wires in Figures 2b, c were not different from those verified in Figure $2 \mathrm{a}$ for solution $1\left(\mathrm{pH}=3.0\right.$ and no $\left.\mathrm{F}^{-}\right)$. The OCP values of the SS wires were always more positive than the $\mathrm{Ni}$-Ti ones and approximately constant during the experiment period, despite the $\mathrm{pH}$ and the $\boldsymbol{C}_{F}$ values, indicating that the $\mathrm{CrO}_{2}$ film may still be stable at these conditions.

On the other hand, several changes could be noted for the $\mathrm{Ni}-\mathrm{Ti}$ wires immersed in the same solutions. It can be verified that, at $\mathrm{pH}=3.0$ and in solutions 3 and 4 (Figure 2b), the Ni-Ti wires present OCP values much more negatives that those observed for SS wires, immersed in the same solutions. It can also be noted that the OCP values for the $\mathrm{Ni}-\mathrm{Ti}$ wires immersed in solution 4 (containing $1000 \mathrm{mg} . \mathrm{L}^{-1} \mathrm{~F}^{-}$) are even more negative than those obtained for solution 3 (containing $100 \mathrm{mg} . \mathrm{L}^{-1} \mathrm{~F}^{-}$), for this same wire. These results indicate that the presence of fluoride and its concentration in solution $\left(\boldsymbol{C}_{\boldsymbol{F}}\right)$ may affect the corrosion of Ni-Ti alloys. Equally, in the experiments performed at $\mathrm{pH}=5.0$ (Figure 2c), the Ni-Ti wires immersed in solutions containing $\mathrm{F}^{-}$(solutions 5 and 6 of Table 3 ) presented OCP values more negative than the SS ones in the same conditions. This behavior agrees to what has been observed in Figure $2 \mathrm{~b}$ for the experiments in $\mathrm{pH}=3.0$, although the results among the $\mathrm{Ni}$-Ti wires in solution 5 and the SS wires in both solutions 5 and 6 were not statistically different $(\mathrm{p}>0.05)$ at $\mathrm{pH}=5.0$. Even though the small defects observed in Figure 1b could also have influenced on the Ni-Ti performance in fluoride containing media, the results shown in Figures $2 \mathrm{~b}$, c indicate that there must be a direct correlation between $\mathrm{pH}$ value and $\mathrm{F}^{-}$concentration, which can favor (or not) the Ti-depassivation in the alloy.

It has been already shown that the corrosion of wires containing $\mathrm{Ti}$ in artificial saliva containing $\mathrm{NaF}$ was under 100 times larger than that tested in fluoride-free artificial saliva $^{26}$. Moreover, the OCP values of pure titanium and titanium alloys strongly decreased after 24 hours immersed in fluoridated-acidified Fusayama Meyer saliva ${ }^{31}$. Concerning the effect of fluoride concentration Lee et al. ${ }^{23}$, have shown a significant influence $(\mathrm{p}<0.001)$ of the $\boldsymbol{C}_{\boldsymbol{F}}$ on the corrosion resistance of $\mathrm{Ni}$-Ti wires, regardless of archwire manufacturer. Similar results were described by Robin and Meireles ${ }^{32}$ for Ti samples in artificial saliva with different $\mathrm{pH}$ values and $\mathrm{F}^{-}$concentration. All of these results are in agreement with those shown in the present work.

It is also important to remember that the measured OCP values are also related to the surface morphology of the wires, which can be dependent on their finishing processes. In the present work, however, the finishing treatment did not seem to cause any significant differences in the OCP measurements of SS and Ni-Ti wires in acid artificial saliva. The differences were observed only in the presence of $\mathrm{F}^{-}$ions.

\subsection{Design 1 results}

After 15 and 30 days of exposition in solutions no. 1 and 2 of Table 3 (Design 1), it was observed no weight loss for any of the studied wires, regardless the $\mathrm{pH}$ value used, considering the uncertainty of the used balance $(0.1 \mathrm{mg})$. Moreover, the $\boldsymbol{C}_{N i}$ determined in the resulting solutions were below the detection limit (DL) of the analysis method $\left(\mathrm{DL}=0.42 \mathrm{mg} . \mathrm{L}^{-1}=0.02 \mathrm{~mol} . \mathrm{L}^{-1}\right)$. These results suggest that, for the kind of saliva used in this work, $\boldsymbol{p H}$ and $\boldsymbol{t}$ are not causing significant corrosion in both orthodontic SS and $\mathrm{Ni}$-Ti wires.

The present results agree with the work of Kutha et al. ${ }^{11}$, who verified that there was no significant difference in $\mathrm{Ni}^{2+}$ released from $\mathrm{SS}$ and $\mathrm{Ni}-\mathrm{Ti}$ wires in artificial saliva ( $\mathrm{pH}=3.5$ ) after 28 days of immersion. On the other hand, Huang et al. ${ }^{4}$ have shown that the decrease in the artificial saliva $\mathrm{pH}$ from 3.75 to 2.50 and an increase in the immersion time caused an increase in $\mathrm{Ni}^{2+}$ release of a $\mathrm{Ni}-\mathrm{Ti}$ alloy. They have also shown that their result was dependent on the wire manufacturers. Even though we have used a Ni-Ti archwire obtained from a different manufacturer and a different 
saliva solution, it is possible to note that, at the $\mathrm{pH}$ values used in the present work (3.0 and 5.0), which were above the more acidic $\mathrm{pH}$ value used for Huang et al. ${ }^{4}$, only very small $\boldsymbol{C}_{N i}$ were released. These results agree with the OCP measurements observed in Figure 2 a where only small differences could be verified for both wires in the studied $\mathrm{pH}$ values, indicating a trend, although no significant, of increasing the $C_{N i}$ with decreasing the $\mathrm{pH}$. Once more, the finishing treatment did not seem to cause any significant differences in the $\boldsymbol{C}_{N i}$ measurements of SS and Ni-Ti wires in acid artificial saliva.

Therefore, based on the amount of $\mathrm{Ni}^{2+}$ released in the artificial saliva studied in the present work (in both $\mathrm{pH}$ values), both wires could be clinically used during the time that these experiments lasted (30 days). It means that the $\boldsymbol{C}_{N i}$ released from both orthodontic wires (SS and Ni-Ti) used in this study may not be of clinical significance for most patients, even at 30 days of exposition.

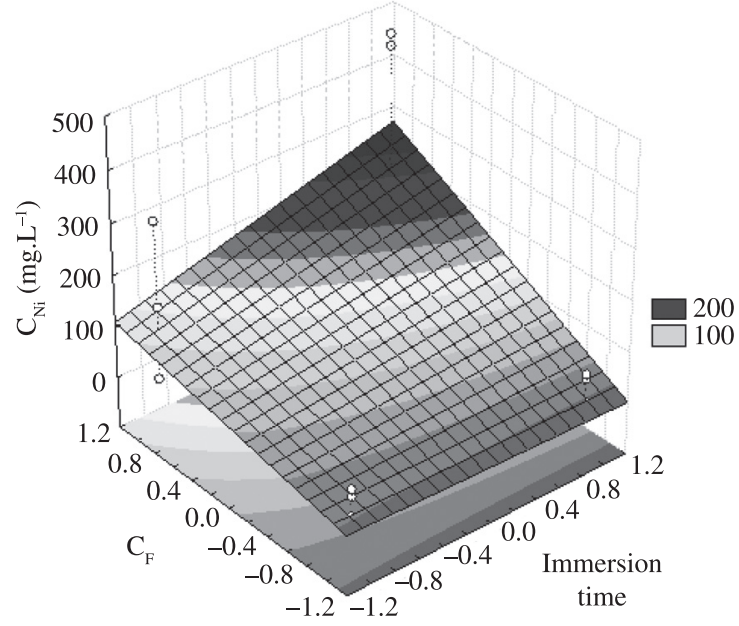

(a)

\subsection{Design 2 results}

For the experiments carried out using Design 2, different results were observed for both $\boldsymbol{C}_{N i}$ and $\Delta \boldsymbol{m}$. The result model obtained for $\boldsymbol{C}_{N i}$, estimated from the experiments performed in the solutions 3 and 4 described in Table 3 (solutions containing $\mathrm{F}^{-}, \mathrm{pH}=3.0$ ), is represented by the fitted surface response diagram shown in Figure 3 and defined by Equation 2. The fitting shows, at a confidence level of $95 \%$ and $\mathrm{R}^{2}=96 \%$, that all the studied parameters, as well as the interactions among them, significantly stimulated the $C_{N i}$ released by the corrosion of the orthodontic wires. This variable was more influenced by $\boldsymbol{w}(\mathrm{p}<0.00001)$, followed by $C_{F}(\mathrm{p}<0.0001)$ and by the interaction between $\boldsymbol{w}$ and $\boldsymbol{C}_{\boldsymbol{F}}$ $(\mathrm{p}<0.0001)$. It means that, comparing both wires, the $\mathrm{Ni}-\mathrm{Ti}$ wires would be easier corroded than the SS ones, mainly in a solution containing high $\boldsymbol{C}_{F}$.

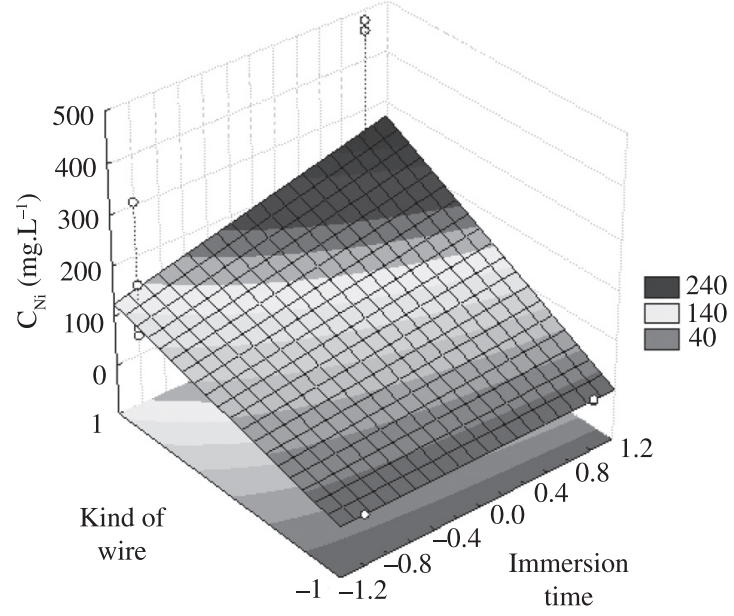

(b)

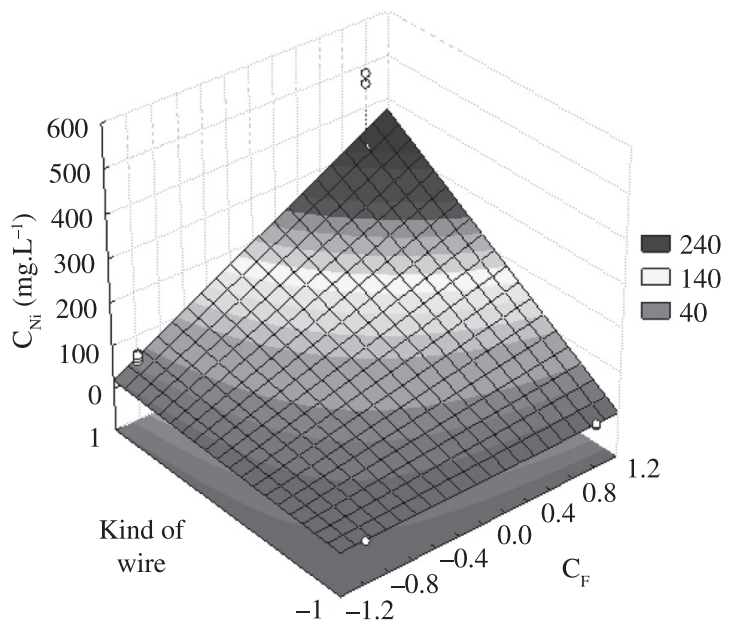

(c)

Figure 3. Fitted surfaces of standardized effects for $\boldsymbol{C}_{N i}\left(\mathrm{mg} \cdot \mathrm{L}^{-1}\right)$ at the conditions of Design 2 (Table 5) for pH solution $=3.0$ : (a) Influence of $\boldsymbol{C}_{F}$ and $\boldsymbol{t}$; (b) Influence of $\boldsymbol{w}$ and $\boldsymbol{t}$; (c) Influence of $\boldsymbol{w}$ and $\boldsymbol{C}_{\boldsymbol{F}}$. 


$$
\begin{aligned}
& \hat{C_{N i}}=100+31 t+75 C_{F}+98 w+30 t C_{F} \\
& +30 t w+74 C_{F} w+30 t C_{F} w
\end{aligned}
$$

Figure 3 presents the response surface for the proposed model and shows the tendency for increasing the studied response variable $\left(\boldsymbol{C}_{N i}\right)$ as the darkest part of the figure. Figure 3 a shows the effects of a concurrent variance of $\boldsymbol{C}_{F}$ and $\boldsymbol{t}$ on $\boldsymbol{C}_{N i}$. There is a strong and positive interaction between both parameters to increase $C_{N i}$, which means that a simultaneous increase of $\boldsymbol{t}$ and $\boldsymbol{C}_{\boldsymbol{F}}$ would favor the corrosion process of both orthodontic wires. Analyzing the influences of $\boldsymbol{t}$ and $\boldsymbol{w}$, and $\boldsymbol{C}_{\boldsymbol{F}}$ and $\boldsymbol{w}$ (Figures 3b, c, respectively) on $C_{N i}$, a strong and significant increase in $\mathrm{Ni}^{2+}$ release can be observed when Ni-Ti wires are used, for both large $t$ and $\boldsymbol{C}_{\boldsymbol{F}}$ values. The Ni-Ti wires are represented in these figures as +1 level, while the SS wires are presented as the -1 level (parameter " $X_{3}$ " in Table 5). Since this is not a numerical parameter, the results presented in Figures $3 \mathrm{~b}$, c are qualitative and only the extreme levels are expressed, representing the $\mathrm{SS}$ and $\mathrm{Ni}-\mathrm{Ti}$ wires $(-1$ and +1 levels, respectively). These results show that, in the conditions of these experiments, the corrosion of Ni-Ti wires is more intense than the SS ones.

On the other hand, no significant effect of the studied parameters on $\Delta \boldsymbol{m}$ could be noted, even though mass differences have been measured (which was not obtained for Design 1). However, similar trends were observed in the surface responses plotted for this variable (Figure 4). It indicated that the weight loss probably follows the same trends observed for $C_{N i}$, confirming that the corrosion of Ni-Ti wires at $\mathrm{pH}=3.0$ occurs at larger extent when compared to that observed for SS ones, mainly at higher $\boldsymbol{C}_{F}$ and $\boldsymbol{t}$ values.

An increase in the $\mathrm{pH}$ values decreased the orthodontic wires corrosion, as measured in terms of $\boldsymbol{C}_{N i}$ and $\Delta \boldsymbol{m}$. However, the presence of $\mathrm{F}^{-}$ions (solutions 5 and 6 of Table 1) was directly responsible for the corrosion of the wires, even at $\mathrm{pH}=5.0$. At a confidence level of $95 \%$ and $\mathrm{R}^{2}=96 \%$, only the parameters $\boldsymbol{C}_{\boldsymbol{F}}(\mathrm{p}<0.00006)$ and $\boldsymbol{w}$ $(\mathrm{p}<0.00004)$, as well as the interaction between them

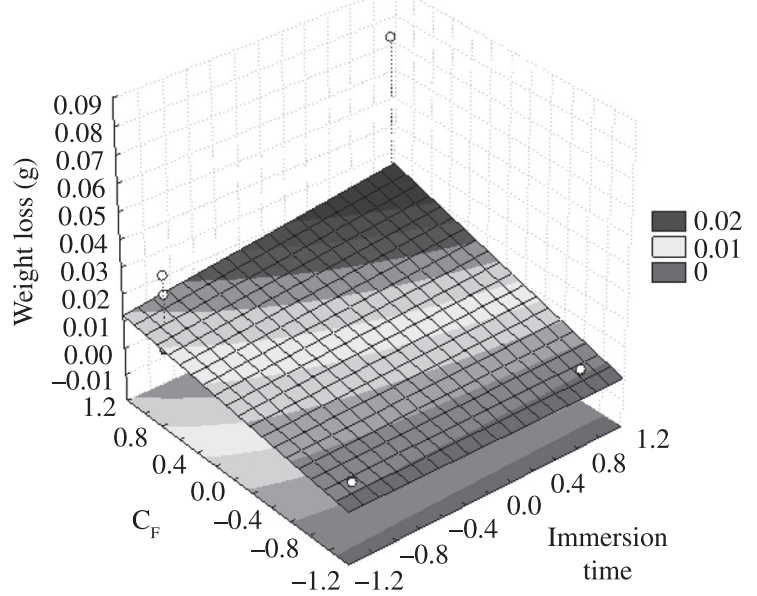

(a)

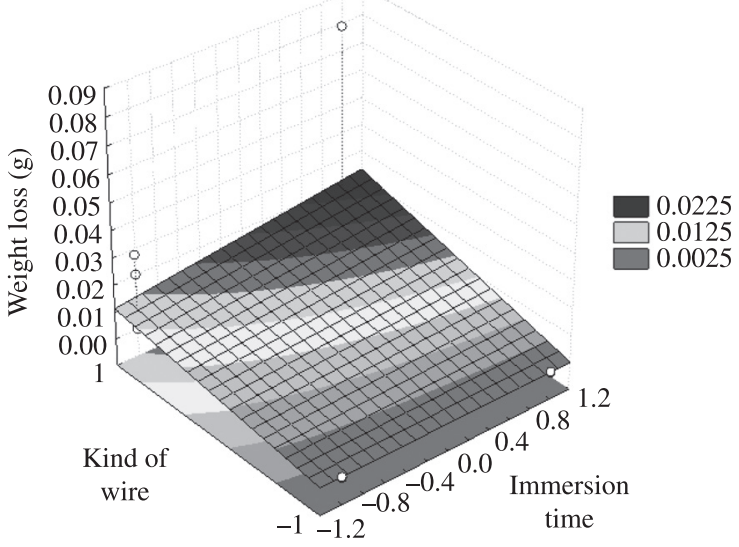

(b)

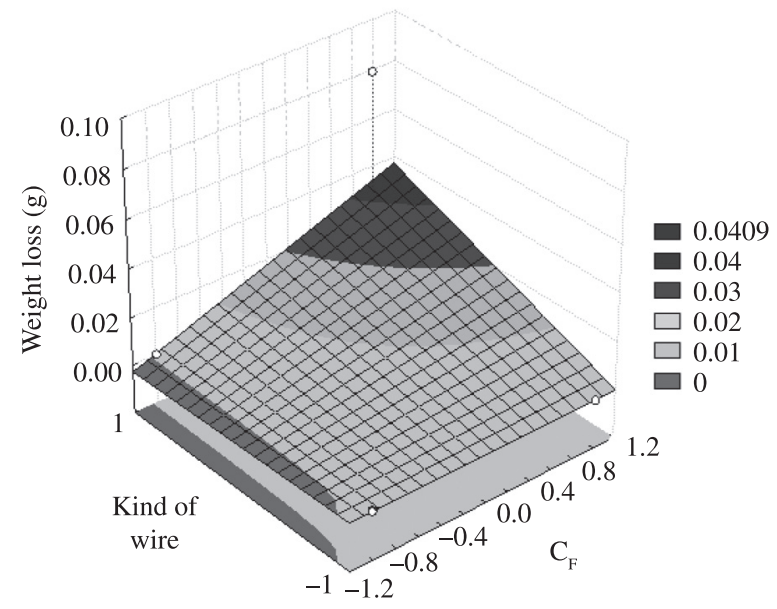

(c)

Figure 4. Fitted surfaces of standardized effects for $\Delta \boldsymbol{m}(\mathrm{g})$ at the conditions of Design 2 (Table 5) for $\mathrm{pH}$ solution = 3.0: (a) Influence of $C_{F}$ and $t$; (b) Influence of $\boldsymbol{w}$ and $t$; (c) Influence of $\boldsymbol{w}$ and $\boldsymbol{C}_{\boldsymbol{F}}$. 
( $\mathrm{p}<0.00001)$, affected the $\boldsymbol{C}_{N i}$ released during the corrosion experiments, confirming that $\mathrm{Ni}-\mathrm{Ti}$ wires would be easily corroded in a solution containing high $C_{F}$, even at $\mathrm{pH}=5.0$. Equation 3 and the response surfaces for the variable $\boldsymbol{C}_{N i}$ (Figure 5) present the final results for this model. It is possible to note by the equations coefficients (the bi in Equation 1) that the corrosion process intensity decreased, when compared to Equation 2. The results show that an increase in the $\boldsymbol{C}_{\boldsymbol{F}}$ favors the corrosion process, mainly for $\mathrm{Ni}$-Ti wires, regardless the exposition time.

$\hat{C_{N i}}=3,0+1,9 C_{F}+2,0 w+2,4 C_{F} w$

Similarly to what have been noticed before, no significant effect of the studied parameters on $\Delta \boldsymbol{m}$ could be noted, although all 16 experiments have presented mass differences. However, some trends could also be seen (Figure 6) and, for these conditions, $\Delta m$ presents a non statistical trend to increase with the interaction between $t$ and $C_{F}$, mainly for Ni-Ti wires.

By analyzing the above mentioned results, the relationship between the $\boldsymbol{C}_{\boldsymbol{F}}$ and the $\mathrm{pH}$ of the saliva solution for the integrity of the $\mathrm{TiO}_{2}$ passive layer, earlier indicated by the OCP experiments in Figures $2 b$, c, becomes clearer. In agreement with the results of Robin and Meireles ${ }^{32}$ and Kao and Huang ${ }^{12}$, the results presented in Figures 3 to 6 show that a decrease in $\mathrm{pH}$ values of an artificial saliva containing $\mathrm{F}^{-}$reduces the corrosion resistance of the Ni-Ti wires, since the surface passive film on these archwires becomes severely damaged by fluoride ions, favouring the passive $\mathrm{TiO}_{2}$ film breakdown. Moreover, this effect becomes more intense with increasing the $C_{F}$, as shown by Lee et al. ${ }^{23}$. Small $C_{F}$ present in acidic medium is enough to form fluoridric acid (HF) molecules, and the dissolution of the oxide film depends on the presence of HF and other species that are formed at low $\mathrm{pH}$ values. HF concentration above $30 \mathrm{mg} . \mathrm{L}^{-1}$ can react with the $\mathrm{TiO}_{2}$ film and destroy $\mathrm{it}^{25,32,33}$. The $\mathrm{TiO}_{2}$

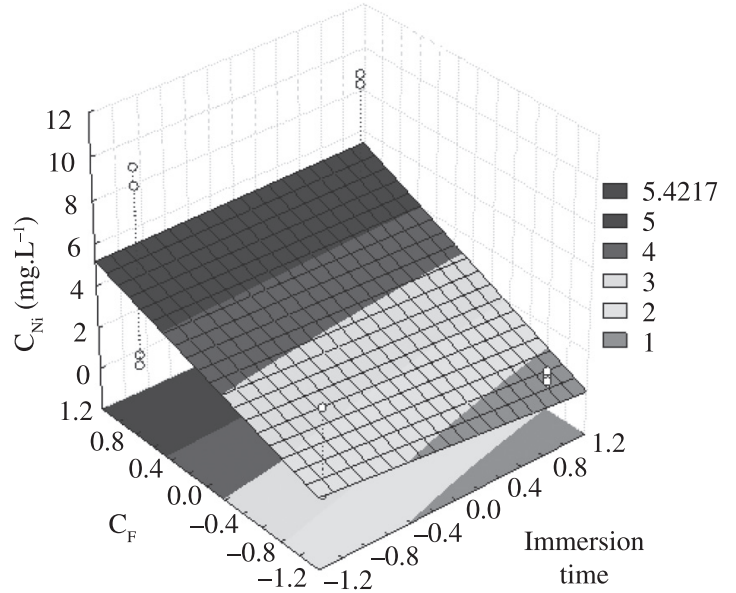

(a)

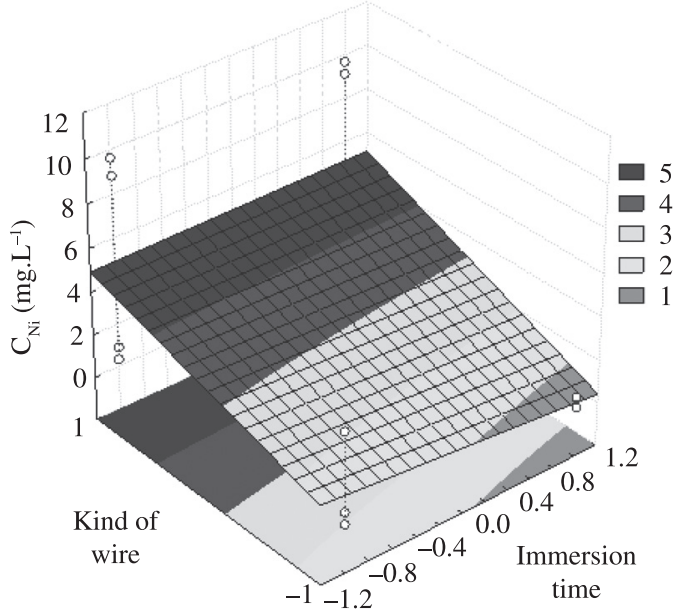

(b)

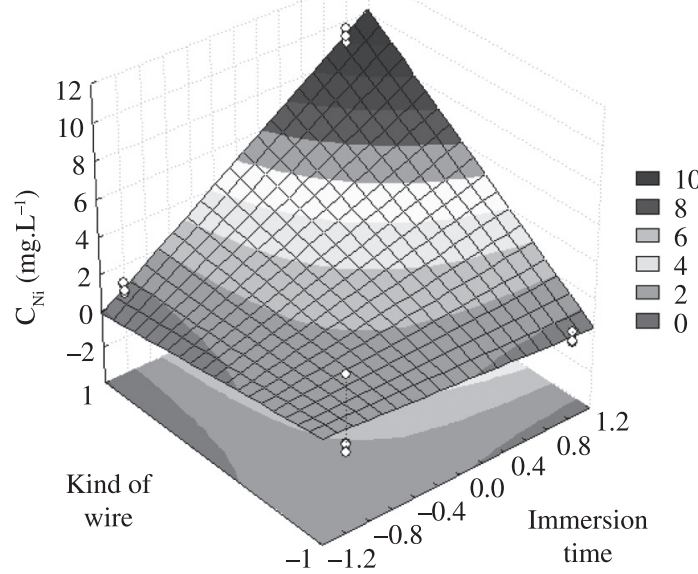

(c)

Figure 5. Fitted surfaces of standardized effects for $\boldsymbol{C}_{N i}\left(\mathrm{mg} \cdot \mathrm{L}^{-1}\right)$ at the conditions of Design 2 (Table 5) for pH solution $=5.0$ : (a) Influence of $\boldsymbol{C}_{F}$ and $\boldsymbol{t}$; (b) Influence of $\boldsymbol{w}$ and $\boldsymbol{t}$; (c) Influence of $\boldsymbol{w}$ and $\boldsymbol{C}_{F}$. 
passive layer is completely degraded at acidic $\mathrm{pH}$ saliva containing $\mathrm{F}^{-}$concentration of approximately $500 \mathrm{mg} . \mathrm{L}^{-1}$, due to the formation of a complex between $\mathrm{Ti}_{\text {and }} \mathrm{F}^{-[23]}$. It is important to point out that in daily commercial mouthwashes the $\mathrm{F}^{-}$concentration may reach $250 \mathrm{mg} . \mathrm{L}^{-1}$. In a real oral cavity, this effect can be added to other acidic compounds, like formic acid and lactic acid, present in the bacterial plaque, which can contribute to $\mathrm{Ti}$ and $\mathrm{Ti}$-based alloys corrosion in oral cavity ${ }^{34}$.

However, if the $\mathrm{pH}$ is not acid enough this effect can decrease, as it was verified by the coefficient values of Equation 3 when compared to those of Equation 2 for the same parameters effects on the response variable $\left(\boldsymbol{C}_{N i}\right)$. Ahn et al. ${ }^{33}$ have shown that the content of the released metal elements of $\mathrm{Ni}-\mathrm{Ti}$ and $\mathrm{Ni}-\mathrm{Ti}-\mathrm{Cu}$ orthodontic wires during 3-day immersion in $\mathrm{F}^{-}$-containing $\left(<500 \mathrm{mg}\right.$. $\left.\mathrm{L}^{-1}\right)$ acidic ( $\mathrm{pH} \mathrm{6)}$ solution could be considered negligible. Kao and Huang ${ }^{12}$ compared the corrosion behaviour of stainless steel and $\mathrm{Ni}$ - Ti wires in fluoridated artificial saliva at two $\mathrm{pH}$ values, 4 and 6 , and their results indicated a decrease in the corrosion process of both wires at $\mathrm{pH}=6$. Even though, the corrosion of Ni-Ti wires in slightly acid solutions is still dependent on $\boldsymbol{C}_{\boldsymbol{F}}$, as can also be seen in the present study and in the work of Lee et al. ${ }^{23}$.

Although the corrosion of SS wires in $\mathrm{F}^{-}$-containing medium was more intense than in solutions 1 and 2 of Table 3 (without $\mathrm{F}^{-}$ions), the $\boldsymbol{C}_{N i}$ released for this kind of wire in $\mathrm{F}^{-}$-containing solutions were much smaller than the values obtained for the Ni-Ti wires in the same solutions. For example, the values of $\boldsymbol{C}_{N i}$ in the solutions resulting from these experiments in Solution 4 of Table 3, which was the most aggressive solution studied, were $3.58 \mathrm{mg} . \mathrm{L}^{-1}$ (0.21 mol.L $\left.\mathrm{L}^{-1}\right)$ and $468 \mathrm{mg} . \mathrm{L}^{-1}\left(27.50 \mathrm{~mol} . \mathrm{L}^{-1}\right)$ for SS and $\mathrm{Ni}-\mathrm{Ti}$ wires, respectively. These results can also be related to the surface morphology of SS and Ni-Ti wires before testing (Figure 1). Since the SS wires presented low roughness and few surface defects, the intensity of corrosion could have been smaller than that verified for the Ni-Ti ones. Therefore, the corrosion process of $\mathrm{Ni}-\mathrm{Ti}$ wires in acid artificial saliva containing $\mathrm{F}^{-}$ions, a very aggressive medium for Ti-based alloys, could probably have been intensified by the surface defects. However, more experiments are needed to reach a final conclusion about the influence of surface finishing on the corrosion process of these wires.

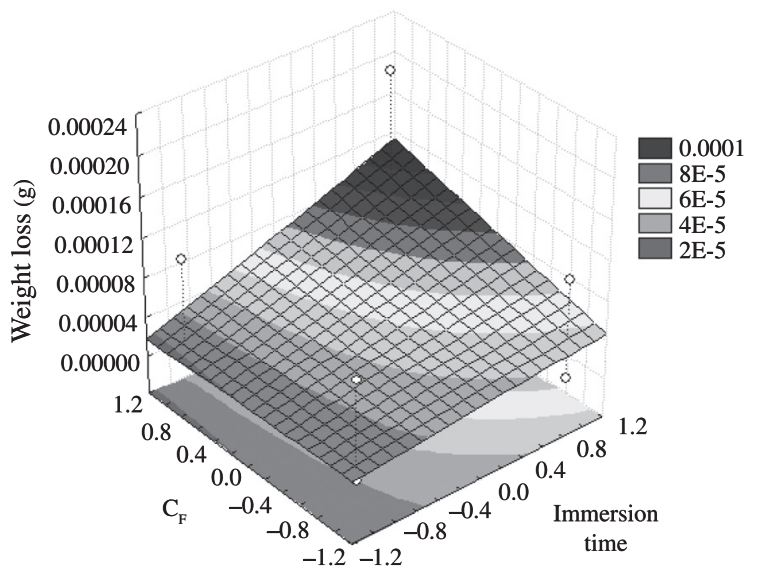

(a)

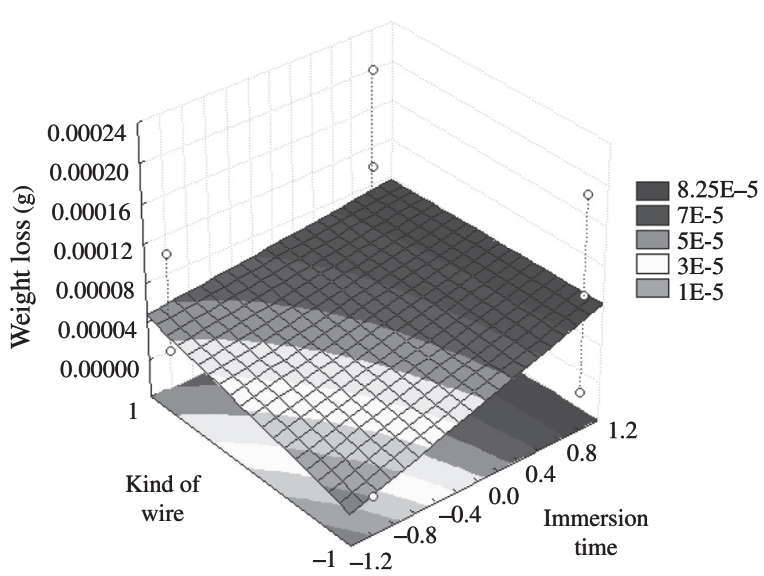

(b)

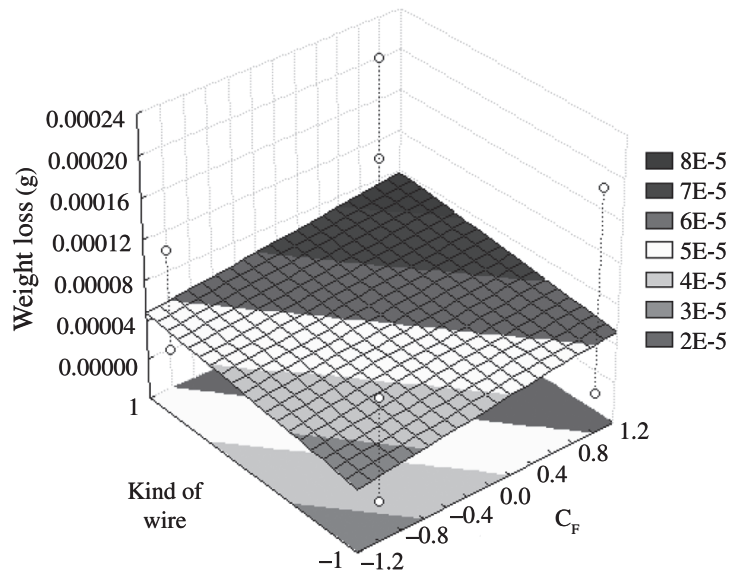

(c)

Figure 6. Fitted surfaces of standardized effects for $\Delta \boldsymbol{m}(\mathrm{g})$ at the conditions of Design 2 (Table 5) for pH solution $=5.0$ : a) Influence of $C_{F}$ and $\left.t ; b\right)$ Influence of $\boldsymbol{w}$ and $t ;$ c) Influence of $\boldsymbol{w}$ and $\boldsymbol{C}_{F}$. 


\subsection{Morphological analysis of the wires after the immersion experiments}

Figure 7 presents the surface morphology of the SS and Ni-Ti wires after 30 days of exposition in solution 4 of Table 3, which have been showed as the most aggressive conditions verified in this work. It can be observed that the corrosion attack to the SS surface (Figure 7a) was less severe than that noted for Ni-Ti wires (Figure 7b), in which cracks in the $\mathrm{TiO}_{2}$ coating can be noted. This result agrees with the OCP data in Figure $2 \mathrm{~b}$ and with the values found for $\boldsymbol{C}_{N i}$ in the studied solution, as presented in Design 2. Yokoyama et al. ${ }^{35}$ have shown that acid treatment causes the Ni-Ti wire to become brittle, and under stress, this wire may fracture. This possibility may increase in presence of $\mathrm{F}^{-}$ions, since these ions cause the breakdown of the protective passivation layer that normally exists on titanium and its alloys, leading to pitting corrosion ${ }^{31}$. However, the morphological effects due to the small pores and cracks observed on the as-received Ni-Ti wires surface (Figure 1b) must also be taken in consideration. These defects may have also contributed to present results in $\mathrm{F}^{-}$-containing acid saliva.

\subsection{Polarization experiments}

Figure 8a shows the results of the polarization curves obtained for the SS and Ni-Ti wires in the Solutions 1 and 2 of Table 3. It is possible to note that the curves of SS wires were shifted to smaller values of current density, when compared to the $\mathrm{Ni}-\mathrm{Ti}$ ones, regardless the $\mathrm{pH}$ values used. This is reflected in their respective corrosion current densities and corrosion rate values, presented in Table 6 , and it means that the SS wires were less susceptible to corrosion in the studied artificial saliva medium than the $\mathrm{Ni}$-Ti wires. Additionally, the effect of changing the $\mathrm{pH}$ to more acidic values was clearly observed for the Ni-Ti wires, whose pitting potential was decreased. Similar results were found by Afshar et al..$^{25}$, which was related to an increase in the corrosion of $\mathrm{Ni}$-Ti wires and, consequently, to the $\mathrm{Ni}^{2+}$ release.

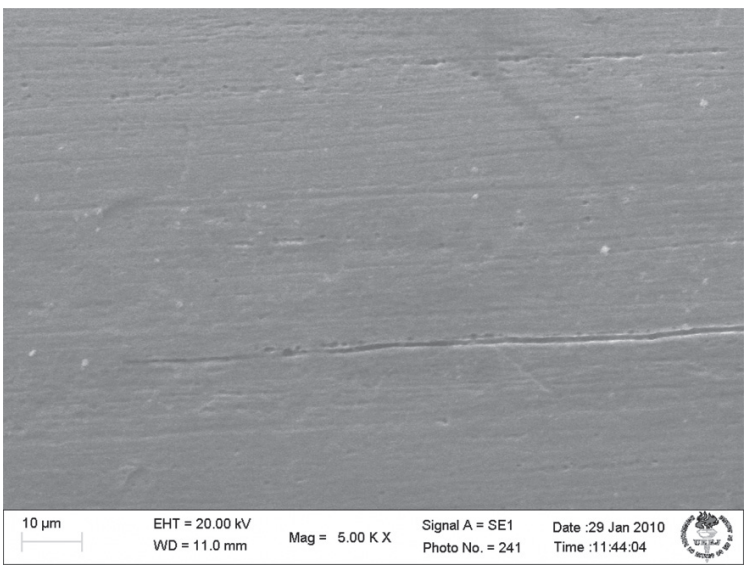

(a)
It is important to point out that the both effects of $\boldsymbol{p H}$ and $\boldsymbol{w}$ could not be noted in a long-time assay as the total immersion experiments performed in Design 1. However, these effects were easily observed in the polarization curves, showing that both kinds of experiments must be used as complementary tools to verify the corrosion processes of orthodontic wires in artificial saliva.

The effects of $\boldsymbol{p} \boldsymbol{H}$ and the $\boldsymbol{C}_{\boldsymbol{F}}$ on the polarization curves of SS wires can be observed in Figure $8 \mathrm{~b}$ and Table 6. It is interesting to note that both parameters present a strong influence in the anodic branches of the polarization curves, which are changed to higher values of current density when $C_{F}$ was increased, mainly at more acidic medium. This result could be related to a change in the corrosion process of this wire, probably due to a decrease in the resistance of the $\mathrm{Cr}_{2} \mathrm{O}_{3}$ layers at these conditions. The proposed mechanism would involve the penetration of $\mathrm{F}^{-}$ions into the metal/oxide film interface, causing pitting corrosion ${ }^{31}$. The direct effect of changing $C_{F}$, however, was less noted at $\mathrm{pH}=3.0$, since both curves were not significantly different. It could indicate a higher influence of $\mathrm{pH}$ in this process, which agrees with the work of Kao and Huang ${ }^{12}$. Additionally, the corrosion current densities and the corrosion rates values obtained from these experiments and shown in Table 6 were not significantly different $(\mathrm{p}>0.05)$ from those earlier presented in Figure 8a.

Figure 8c presents the effects of $\boldsymbol{p H}$ and the $\boldsymbol{C}_{\boldsymbol{F}}$ in the polarization curves of Ni-Ti wires in Solutions 3 to 6 of Table 3. It is possible to see that most of the curves are changed to higher values of current density when the $\mathrm{pH}$ was decreased and $\boldsymbol{C}_{\boldsymbol{F}}$ was increased, which indicates that these conditions stimulated the corrosion of $\mathrm{Ni}-\mathrm{Ti}$ wires. Similar to the findings presented in Figure $8 \mathrm{~b}$, there is a strong influence of the studied parameters in the anodic branch of the polarization curves, probably due a change in the corrosion process of these wires. However, the curve obtained for the smallest $\mathrm{pH}$ and highest $\boldsymbol{C}_{\boldsymbol{F}}$ values have also presented a higher shift in the cathodic branch, showing that this condition may have also affected the corrosion kinetics more intensively. Yokoyama et al..$^{35}$ proposed that the mechanism of corrosion might be from hydrogen

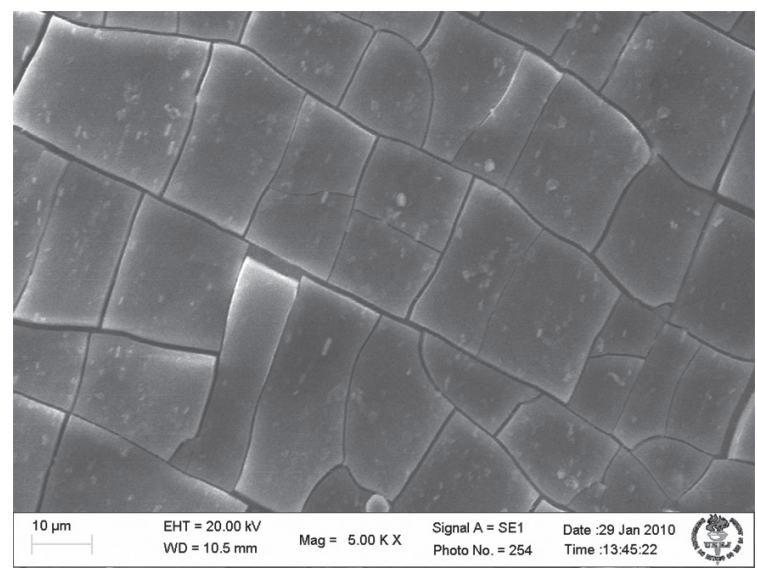

(b)

Figure 7. Surface morphologies of the (a) SS and (b) Ni-Ti wires after 30 days of exposition in artificial saliva solution no. 3 of Table 1. 
adsorption on NiTi wire surface, penetrating into the wire, and enhancing its fragility. This process is increased at low $\mathrm{pH}$ values, and may be improved at high $\boldsymbol{C}_{\boldsymbol{F}}$ values, probably causing the changes observed in the cathodic branch of the polarization curve obtained at $\mathrm{pH}=3.0$ and high $\boldsymbol{C}_{\boldsymbol{F}}$.

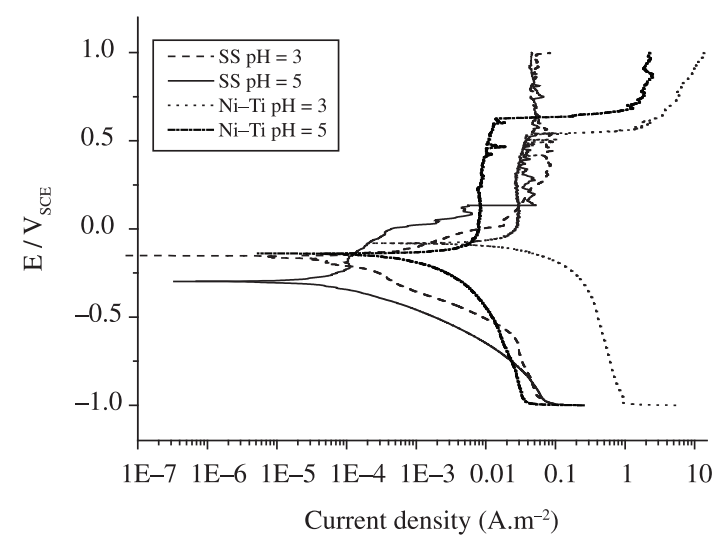

(a)
These results agree to those presented for Design 2 and can also be related to the effect of $\mathrm{pH}$ and $\boldsymbol{C}_{F}$ on the stability of $\mathrm{TiO}_{2}$ layers, presented on the surface of these wires. Evaluating Ti and Ni-Ti alloys, Schiff et al. ${ }^{31}$ reported similar results, when comparing fluoridated acidified saliva,

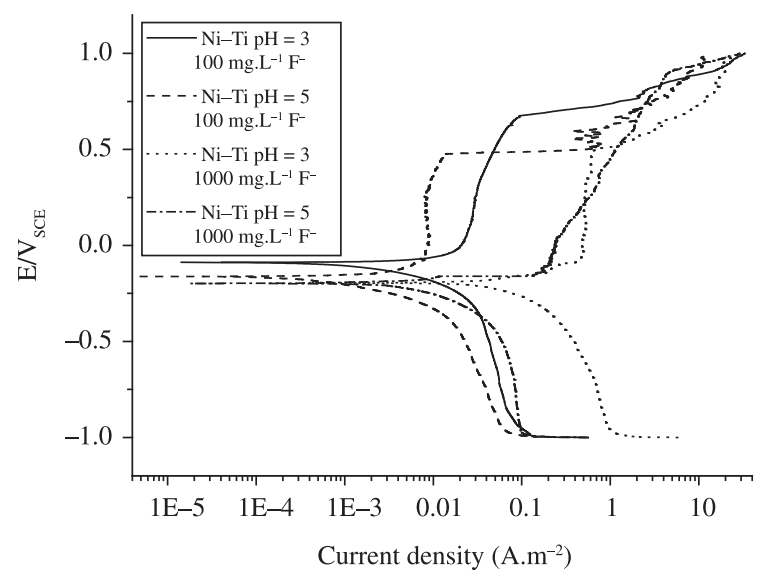

(c)

Figure 8. Polarization curves of (a) SS and Ni-Ti wires immersed in the Solutions 1 and 2 of Table 3; (b) SS wires immersed in Solutions 3 to 6 of Table 3; (c) Ni-Ti wires immersed in Solutions 3 to 6 of Table 3.

Table 6. Tafel parameters and corrosion rates of the $\mathrm{Ni}-\mathrm{Ti}$ and $\mathrm{Cr}-\mathrm{Ni}$ wires immersed in the solutions of Table 1, obtained from the polarization curves (Figures 7 and 8).

\begin{tabular}{|c|c|c|c|c|c|c|}
\hline & Experimental conditions & & $I_{\text {Corr }}\left(\mathrm{A} \mathrm{cm}^{-2}\right)$ & Corrosion rate (mpy) & $\beta_{c}\left(\mathbf{V} \operatorname{dec}^{-1}\right)$ & $\beta_{\mathrm{a}}\left(\mathrm{V} \operatorname{dec}^{-1}\right)$ \\
\hline \multirow{6}{*}{$\begin{array}{l}\mathrm{Ni}-\mathrm{Ti} \\
\text { wires }\end{array}$} & \multirow{2}{*}{$\begin{array}{l}\text { Solutions } 1 \text { and } 2 \\
\text { (without } \mathrm{F}^{-} \text {íons) }\end{array}$} & $\mathrm{pH}=3.0$ & $5.44 \times 10^{-6}$ & $1.26 \times 10^{-1}$ & 0.043 & 0.092 \\
\hline & & $\mathrm{pH}=5.0$ & $3.60 \times 10^{-7}$ & $8.34 \times 10^{-3}$ & 0.101 & 0.065 \\
\hline & \multirow{2}{*}{$\begin{array}{l}\text { Solutions } 3 \text { and } 5 \\
\left(\mathrm{C}_{F}=100 \mathrm{mg} \cdot \mathrm{L}^{-1}\right)\end{array}$} & $\mathrm{pH}=3.0$ & $8.02 \times 10^{-7}$ & $2.03 \times 10^{-2}$ & 0.053 & 0.112 \\
\hline & & $\mathrm{pH}=5.0$ & $3.34 \times 10^{-7}$ & $7.75 \times 10^{-3}$ & 0.094 & 0.995 \\
\hline & \multirow{2}{*}{$\begin{array}{l}\text { Solutions } 4 \text { and } 6 \\
\left(\mathrm{C}_{F}=1000 \mathrm{mg} \cdot \mathrm{L}^{-1}\right)\end{array}$} & $\mathrm{pH}=3.0$ & $5.71 \times 10^{-6}$ & $1.32 \times 10^{-1}$ & 0.047 & 0.074 \\
\hline & & $\mathrm{pH}=5.0$ & $4.65 \times 10^{-6}$ & $1.08 \times 10^{-1}$ & 0.095 & 0.055 \\
\hline \multirow{6}{*}{ SS wires } & \multirow{2}{*}{$\begin{array}{l}\text { Solutions } 1 \text { and } 2 \\
\text { (without } \mathrm{F}^{-} \text {íons) }\end{array}$} & $\mathrm{pH}=3.0$ & $4.93 \times 10^{-8}$ & $1.25 \times 10^{-3}$ & 0.070 & 0.191 \\
\hline & & $\mathrm{pH}=5.0$ & $3.22 \times 10^{-8}$ & $8.14 \times 10^{-4}$ & 0.063 & 0.069 \\
\hline & \multirow{2}{*}{$\begin{array}{l}\text { Solutions } 3 \text { and } 5 \\
\left(\mathrm{C}_{F}=100 \mathrm{mg} \cdot \mathrm{L}^{-1}\right)\end{array}$} & $\mathrm{pH}=3.0$ & $1.78 \times 10^{-7}$ & $4.49 \times 10^{-3}$ & 0.061 & 0.175 \\
\hline & & $\mathrm{pH}=5.0$ & $5.37 \times 10^{-8}$ & $1.36 \mathrm{E}-03$ & 0.079 & 0.810 \\
\hline & \multirow{2}{*}{$\begin{array}{l}\text { Solutions } 4 \text { and } 6 \\
\left(\mathrm{C}_{F}=1000 \mathrm{mg} \cdot \mathrm{L}^{-1}\right)\end{array}$} & $\mathrm{pH}=3.0$ & $1.90 \times 10^{-8}$ & $4.80 \times 10^{-3}$ & 0.121 & 0.072 \\
\hline & & $\mathrm{pH}=5.0$ & $1.34 \times 10^{-8}$ & $3.39 \times 10^{-4}$ & 0.163 & 0.077 \\
\hline
\end{tabular}




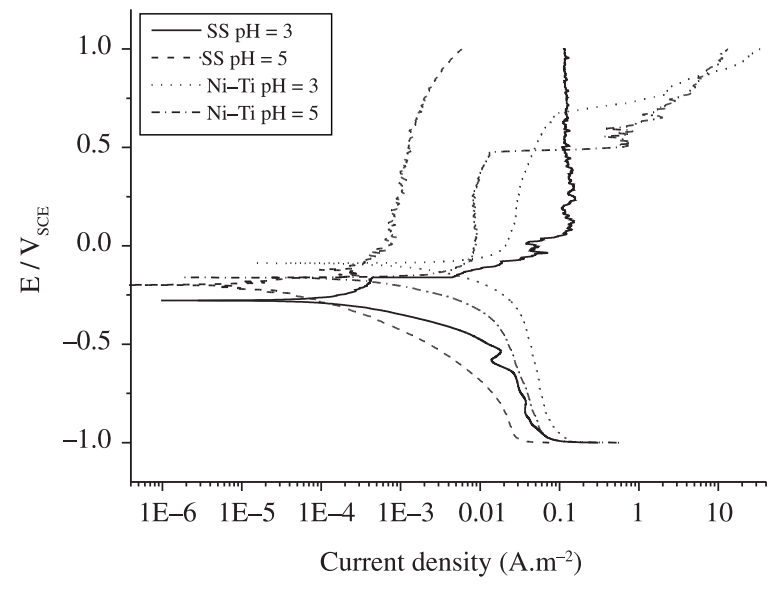

(a)

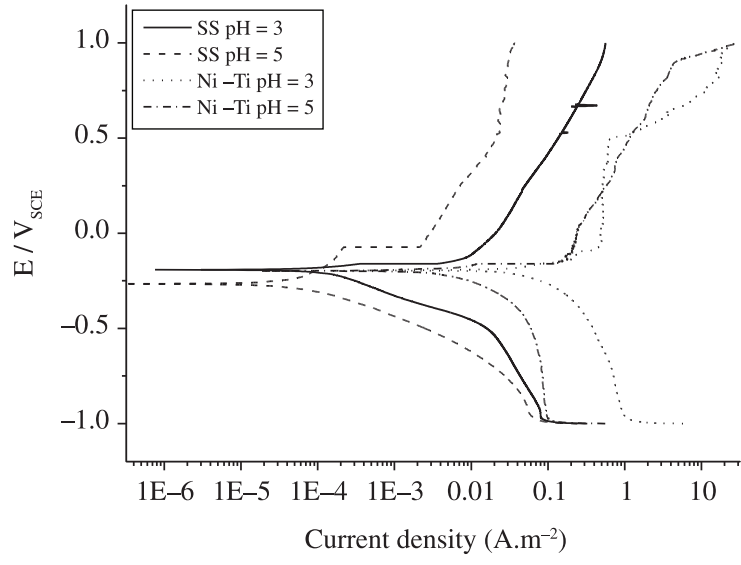

(b)

Figure 9. Influence of $\boldsymbol{w}, \boldsymbol{p H}$ and $\boldsymbol{C}_{\boldsymbol{F}}$ on the polarization curves of SS and Ni-Ti wires: (a) $\boldsymbol{C}_{\boldsymbol{F}}=100 \mathrm{mg} \cdot \mathrm{L}^{-1}$; (b) $\boldsymbol{C}_{\boldsymbol{F}}=1000 \mathrm{mg} \cdot \mathrm{L}^{-1}$.

acidified saliva and fluoridated saliva. It is interesting to note that, when $\boldsymbol{C}_{\boldsymbol{F}}=1000 \mathrm{mg} . \mathrm{L}^{-1}$, the curves are almost similar, regardless the $\mathrm{pH}$ used, which suggests that if $\boldsymbol{C}_{F}$ is high, even at $\mathrm{pH}=5$ the corrosion process can be very intense. It agrees to the results of Lee et al. ${ }^{23}$. Even though there are small differences in the corrosion current densities and in the corrosion rates of Ni-Ti wires immersed in solutions with and without $\mathrm{F}^{-}$(Table 6$)$, no statistic significance $(\mathrm{p}>0.05)$ was obtained.

The effects of $\mathrm{pH}$ and the kind of wire $(\boldsymbol{w})$ on the polarization curves are presented in Figure 9. In accordance to the results presented in Figure $8 \mathrm{~b}$, the solution $\mathrm{pH}$ influenced the corrosion process of SS wires to a greater extent than the Ni-Ti wires, mainly for $C_{F}=1000 \mathrm{mg} . \mathrm{L}^{-1}$. It is possible to observe, in Figure 9a, that the polarization curve for SS wire immersed in Solution 5 of Table 3 $\left(\mathrm{pH}=5.0 ; \boldsymbol{C}_{\boldsymbol{F}}=100 \mathrm{mg} \cdot \mathrm{L}^{-1}\right.$ ), was shifted to smaller values of current density. However, there was only one order of difference among the corrosion current densities of the SS and Ni-Ti curves obtained from Solutions 3 and 5 of Table 3 (Table 6). The difference of $\boldsymbol{w}$ is noted in the shape of the curves, since the pitting potential could not be detectable for the SS wires curves, while it is clearly seen in the Ni-Ti curves. Moreover, the influence of $\boldsymbol{w}$ can be easily distinguished for $\boldsymbol{C}_{F}=1000 \mathrm{mg} . \mathrm{L}^{-1}$ (Figure 9b), in which the curves for Ni-Ti wires were moved to higher values of current density. Table 6 shows that the highest corrosion rate (0.132 mpy) was observed for the Ni-Ti wires, immersed in Solution 4 of Table $3\left(\mathrm{pH}=3.0 ; \boldsymbol{C}_{\boldsymbol{F}}=1000 \mathrm{mg} \cdot \mathrm{L}^{-1}\right)$. This result agrees to what has been presented by the Design 2 .

\section{Conclusions}

The in vitro corrosion process of $\mathrm{SS}$ and $\mathrm{Ni}-\mathrm{Ti}$ orthodontic wires in artificial saliva solutions were evaluated using experimental design and response surface methodology. The corrosion of these wires, measured as weight loss and $\boldsymbol{C}_{N i}$ released was not significantly affected by the parameters studied in Design $1(\boldsymbol{w}, \boldsymbol{t}$, and $\boldsymbol{p H})$. In agreement with these results, the OCP measurements of both
SS and Ni-Ti wires were stable and showed anodic values, at potential regions where the $\mathrm{TiO}_{2}$ and $\mathrm{Cr}_{203}$ were not enough deteriorated during the period of this study (30 days).

On the other hand, the presence of $\mathrm{F}^{-}$(Design 2) has significantly increased the $\boldsymbol{C}_{N i}$ released, mainly for the $\mathrm{Ni}-\mathrm{Ti}$ wire. At $\mathrm{pH}=3.0$, there is a positive and high influence of $\boldsymbol{C}_{F}$ and $\boldsymbol{t}$ for these wires, showing that the simultaneous increase of these parameters is dangerous for the integrity of $\mathrm{Ni}-\mathrm{Ti}$ wires. Increasing the $\mathrm{pH}$ value $(\mathrm{pH}=5.0)$, the corrosion process decreased and $\boldsymbol{t}$ was not a significant parameter anymore. Nevertheless, the Ni-Ti wires were more sensitive to the studied corrosion medium than the SS ones, and at this $\mathrm{pH}$ value, the positive effect of $\boldsymbol{C}_{F}$ on $\boldsymbol{C}_{N i}$ still contributes to cause damages to $\mathrm{Ni}-\mathrm{Ti}$ wires. These results corroborated the OCP measurements.

The polarization curves demonstrated that, in the absence of $\mathrm{F}^{-}$ions, the solution $\mathrm{pH}$ seems to affect the corrosion process of $\mathrm{Ni}-\mathrm{Ti}$ wires more intensely than the SS wires. In the presence of $\mathrm{F}^{-}$ions the corrosion process of SS wires was affected mainly by the solution $\mathrm{pH}$. At $\mathrm{pH}=3.0$, the variation of $\boldsymbol{C}_{F}$ caused small differences in the corrosion rate. Concerning the Ni-Ti wires, an increasing in $\boldsymbol{C}_{F}$ caused a very intense corrosion process in these wires, as could be observed by their polarization curves, which were shifted to higher current densities, independent of the medium $\mathrm{pH}$.

Although it was not statistically evaluated, the morphology of the as-received wires might have contributed to the results obtained in this work. Even though the OCP values and the Design 1 responses (variation in $\boldsymbol{w}, \boldsymbol{t}$, and $\boldsymbol{p H}$ ) did not seem to be affected by the differences on the surface finishing treatments of both wires, the presence of small cracks and pores on the Ni-Ti surface could have influenced on the intensity of its corrosion process obtained from Design 2 (variation in $\boldsymbol{w}, \boldsymbol{t}$, and $\boldsymbol{C}_{\boldsymbol{F}}$, mainly at $\mathrm{pH}=3.0$ ). We suggest that the parameter "surface morphology" be also statistically evaluated in future studies concerning the corrosion of orthodontic wires.

Based on the proposed experimental design and on the obtained response surfaces, the SS wires showed a better 
performance in the studied saliva solutions, even at critical conditions $\left(\boldsymbol{C}_{\boldsymbol{F}}=1000 \mathrm{mg} . \mathrm{L}^{-1}\right.$ and $\left.\mathrm{pH}=3.0\right)$, indicating that, at least in terms of corrosion and in the conditions of these experiments, this kind of wire can be clinically used for long-term exposition than the $\mathrm{Ni}$-Ti ones.

\section{References}

1. Cioffi M, Gilliland D, Ceccone G, Chiesa R and Cigada A. Electrochemical release testing of nickel-titanium orthodontic wires in artificial saliva using thin layer activation. Acta Biomaterialia. 2005; 1(6):717-724. PMid:16701852. http:// dx.doi.org/10.1016/j.actbio.2005.07.008

2. Gil FX, Manero JMR and Planell JA. Relevant aspects in the clinical applications of NiTi shape memory alloys. Journal of Material Science - Materials in Medicine 1996; 7(7):403-406. http://dx.doi.org/10.1007/BF00122008

3. Ferreira NA. Comportamento Mecânico e Eletroquímico de Barras de Titânio Soldadas a Laser. [Tese]. Rio de Janeiro: Universidade Estadual do Rio de Janeiro; 2008.

4. Huang HH, Chiu YH, Lee TH, Wu SC, Yang HW, Su KH et al. Ion release from NiTi orthodontic wires in artificial saliva with various acidities. Biomaterials. 2003; 24(20):3585-3592. http:// dx.doi.org/10.1016/S0142-9612(03)00188-1

5. Schiff N, Grosgogeat B, Lissac MR and Dalard F. Influence of fluoridated mouthwashes on corrosion resistance of orthodontics wires. Biomaterials. 2004; 25(19):4535-4542. PMid:15120498. http://dx.doi.org/10.1016/j.biomaterials.2003.11.042

6. Hensten-Pettersen A. Skin and mucosal reactions associated with dental materials. European Journal of Oral Science. 1998; 106(2):707-712. PMid:9584904.

7. Kim HR and Johnson JW. Corrosion of stainless steel, nickel-titanium, coated nickel-titanium, and titanium orthodontic wires. The Angle Orthodontist. 1999; 69(1):39-44. PMid:10022183.

8. Barrett RD, Bishara SER and Quinn JK. Biodegradation of orthodontic appliances .1. Biodegradation of nickel and chromium invitro. American Journal of Orthodontics and Dentofacial Orthopedics. 1993; 103(1):8-14. http://dx.doi. org/10.1016/0889-5406(93)70098-9

9. Oh KT, Hwang CJ, Park YSR and Kim KN. Corrosion of orthodontic wires according to heat treatment conditions. Materials Transactions. 2002; 43(12):3078-3082. http://dx.doi. org/10.2320/matertrans.43.3078

10. Ryhãnen J, Niemi W, Serlo W, Niemelä E, Sándwich P, Pernu $\mathrm{H}$ et al. Biocompatibility of nickel-titanium shape memory metal and its corrosion behavior in human cell cultures. Journal of Biomedical Materials Research. 1997; 35(4):451-457. http:// dx.doi.org/10.1002/(SICI)1097-4636(19970615)35:4\%3C451 ::AID-JBM5\%3E3.0.CO;2-G

11. Kuhta M, Pavlin D, Slajc M, Varga S, Lapter-Varga MR and Slaj M. Type of archwire and level of acidity: effects on the release of metal ions from orthodontic appliances. The Angle Orthodontist. 2009; 79(1):102-110. PMid:19123703. http:// dx.doi.org/10.2319/083007-401.1

12. Kao C-TR and Huang T-H. Variations in surface characteristics and corrosion behaviour of metal brackets and wires in different electrolyte solutions. European Journal of Orthodontics. 2010; 32(5):555-560. PMid:20139132. http:// dx.doi.org/10.1093/ejo/cjp146

\section{Acknowledgements}

The authors would like to thank the Rio de Janeiro Research Foundation (FAPERJ), the Brazilian National Research Council (CNPq), and the State University of Rio de Janeiro (UERJ) - Prociência Program - for financial support.

13. Eliades T, Zinelis S, Papadopoulos M, Eliades GR and Athanasiou AE. Nickel content of as-received and retrieved NiTi and stainless steel archwires: assessing the nickel release hypothesis. Angle Orthodontist. 2004; 74(2):151-154. PMid:15132439.

14. Eliades T, Trapalis C, Eliades GR and Katsavrias E. Salivary metal levels of orthodontic patients: a novel methodological and analytical approach. European Journal of Orthodontics. 2003; 25(1):103-106. http://dx.doi.org/10.1093/ ejo/25.1.103

15. Huang T-H, Yen C-CR and Kao C-T. Comparison of ion release from new and recycled orthodontic brackets. American Journal of Orthodontics and Dentofacial Orthopedics. 2001; 120(1):68-75. PMid:11455381. http:// dx.doi.org/10.1067/mod.2001.113794

16. Amini F, Jafari A, Amini PR and Sepasi S. Metal ion release from fixed orthodontic appliances - an in vivo study. European Journal of Orthodontics. 2012; 34(1):126-130. PMid:21303810. http://dx.doi.org/10.1093/ejo/cjq181

17. Eliades TR and Athanasiou AE. Intraoral aging of orthodontic alloys: implications for corrosion potential, nickel release and biocompatibility. Angle Orthodontist. 2002; 72(3):222-237. PMid:12071606.

18. Senna LFR and Luna AS. Experimental design and response surface analysis as available tools for statistical modelling and optimization of electrodeposition processes. In: Sebayang D and Hasan SBH. Electroplating. In Tech Open Access Edition. Croatia; 2011. http://dx.doi.org/10.5772/34310

19. Associação Brasileira de Normas Técnicas-ABNT. NBR 5601: Stainless steels: classification by chemical composition. ABNT; 2012.

20. American Society for Testing and Materials - ASTM. Designation F2063-05: Standard specification for wrought nickel-titanium shape memory alloys for medical devices and surgical implants. ASTM; 2012.

21. Cawson RAR and Odell EW. Essentials of Oral Pathology and Oral Medicine. 7th ed. Hong Kong: Churchill Livingstone; 1998. p. 36-52.

22. Huang H-H. Variation in surface topography of different NiTi orthodontic archwires in various commercial fluoride-containing environments. Dental Materials. 2007; 23(1):24-33. PMid:16417915. http://dx.doi. org/10.1016/j.dental.2005.11.042

23. Lee TH, Huang TK, Lin SY, Chen LK, Chou MYR and Huang HH. Corrosion resistance of different nickel-titanium archwires in acidic fluoride-containing artificial saliva. Angle Orthodontist. 2010; 80(3):547-553. PMid:20050751. http:// dx.doi.org/10.2319/042909-235.1

24. Pourbaix M. Atlas of Electrochemical Equilibria in Aqueous Solutions. Brussels: National Association of Corrosion Engineering Ed.; 1987.

25. Afshar A, Shirazi MR and Fakheri E. Effects of temperature and $\mathrm{pH}$ on the corrosion behavior of NiTi orthodontic arch wire 
in artificial saliva. In: Proceedings of the 16th International Corrosion Congress; 2005; Beijing. Beijing; 2005.

26. Lee TH, Wang CC, Huang TK, Chen LK, Chou MYR and Hung HH. Corrosion resistance of titanium-containing dental orthodontic wires in fluoride-containing artificial saliva. Journal of Alloys and Compounds. 2009; 488(1):482-489. http://dx.doi.org/10.1016/j.jallcom.2009.09.015

27. Denes JR and Gabris K. Results of a 3-year oral hygiene program, including amine fluoride products, in patients treated with fixed orthodontic appliances. European Journal of Orthodontics. 1991; 13(9):129-133. PMid:2055251.

28. Boyd RL. Comparison of 3 self-applied topical fluoride preparations for control of decalcification. Angle Orthodontist. 1993; 63(1):25-30. PMid:8507027.

29. Huang HH. Effects of fluoride concentration and elastic tensile strain on the corrosion resistance of commercially pure titanium. Biomaterials. 2002; 23(1):59-63. http://dx.doi. org/10.1016/S0142-9612(01)00079-5

30. Harzer W, Schroter A, Gedrange TR and Muschter F. Sensitivity of titanium brackets to the corrosive influence of fluoride-containing toothpaste and tea. The Angle Orthodontist. 2001; 71(4):318-323. PMid:11510642.
31. Schiff N, Grosgogeat B, Lissac MR and Dalard F. Influence of fluoride content and $\mathrm{pH}$ on the corrosion resistance of titanium and its alloys. Biomaterials. 2002; 23(9):1995-2002. http:// dx.doi.org/10.1016/S0142-9612(01)00328-3

32. Robin AR and Meirelis JP. Influence of fluoride concentration and $\mathrm{pH}$ on corrosion behavior of titanium in artificial saliva. Journal of Applied Electrochemistry. 2007; 37(4):511-517. http://dx.doi.org/10.1007/s10800-006-9283-z

33. Ahn HS, Kim MJ, Seol HJ, Lee JH, Kim HIR and Kwon YH. Effect of $\mathrm{pH}$ and temperature on orthodontic NiTi wires immersed in acidic fluoride solution. Journal of Biomedical Materials Research Part B: Applied Biomaterials. 2006; 79B(1):7-15. PMid:16470830. http://dx.doi.org/10.1002/jbm.b.30505

34. Koike MR and Fujii $\mathrm{H}$. The corrosion resistance of pure titanium in organic acids. Biomaterials. 2001; 22(21):2931-2936. http:// dx.doi.org/10.1016/S0142-9612(01)00040-0

35. Yokoyama K, Ogawa T, Asaoka K, Sakai JR and Nagumo M. Degradation of tensile strength of $\mathrm{Ni}-/ \mathrm{Ti}$ superelastic alloy due to hydrogen absorption in methanol solution containing hydrochloric acid. Material Science Engineer A 2003; 360(1-2):153-159. http://dx.doi.org/10.1016/S09215093(03)00403-9 